\title{
PDAC-derived exosomes enrich the microenvironment in MDSCs in a SMAD4-dependent manner through a new calcium related axis
}

\author{
Daniela Bassoํㅡㄹ Elisa Gnatta ${ }^{1}$, Andrea Padoan ${ }^{1}$, Paola Fogar ${ }^{1}$, Sara Furlanello ${ }^{1}$, \\ Ada Aita1, Dania Bozzatoํ, Carlo-Federico Zambon'², Giorgio Arrigoni2,3, Chiara \\ Frasson ${ }^{4}$, Cinzia Franchin ${ }^{2,3}$, Stefania Moz ${ }^{1}$, Thomas Brefort ${ }^{5,6}$, Thomas Laufer ${ }^{6}$, \\ Filippo Navaglia ${ }^{1}$, Sergio Pedrazzoli, Giuseppe Basso ${ }^{4}$ and Mario Plebani ${ }^{1}$ \\ ${ }^{1}$ Department of Medicine - DIMED, University of Padova, Padova, Italy \\ 2 Department of Biomedical Sciences, University of Padova, Padova, Italy \\ ${ }^{3}$ Proteomic Center, University of Padova, Padova, Italy \\ ${ }^{4}$ Department of Woman and Child Health, Oncohematology Laboratory, University of Padova, Padova, Italy \\ ${ }^{5}$ Eurofins Medigenomix GmbH, Ebersberg, Germany \\ ${ }^{6}$ Comprehensive Biomarker Center GmbH (Recently re-named to Hummingbird Diagnostics GmbH), Heidelberg, Germany \\ ${ }^{7}$ Association Wirsung Onlus, Padova, Italy \\ Correspondence to: Daniela Basso, email: daniela.basso@unipd.it
}

Keywords: pancreatic cancer, exosomes, myeloid derived suppressor cells, calcium, SMAD4

Received: March 03, $2017 \quad$ Accepted: August 04, $2017 \quad$ Published: September 13, 2017

Copyright: Basso et al. This is an open-access article distributed under the terms of the Creative Commons Attribution License 3.0 (CC BY

3.0), which permits unrestricted use, distribution, and reproduction in any medium, provided the original author and source are credited.

ABSTRACT

Tumor genetics and escape from immune surveillance concur in the poor prognosis of PDAC. In this study an experimental model was set up to verify whether SMAD4, deleted in about 55\% PDAC and associated with poor prognosis, is involved in determining immunosuppression through Exosomes (Exo). Potential mechanisms and mediators underlying SMAD4-dependent immunosuppression were evaluated by studying intracellular calcium (Fluo-4), Exo-miRNAs (microarray) and Exoproteins (SILAC). Two PDAC cell lines expressing (BxPC3-SMAD4+) or not-expressing (BXPC3) SMAD4 were used to prepare Exo-enriched conditioned media, employed in experiments with blood donors PBMCs. Exo expanded myeloid derived suppressor cells (gMDSC and mMDSC, flow cytometry) and altered intracellular calcium fluxes in an SMAD4 dependent manner. BXPC3-SMAD4+, but mainly BXPC3 Exo, increased calcium fluxes of PBMCs $(p=0.007)$ and this increased intracellular calcium trafficking characterized mMDSCs. The analysis of de-regulated Exo-miRNAs and transfection experiments revealed hsa-miR-494-3p and has-miR-1260a as potential mediators of SMAD4-associated de-regulated calcium fluxes. Eleven main biological processes were identified by the analysis of SMAD4-associated de-regulated Exo-proteins, including translation, cell adhesion, cell signaling and glycolysis. A reverse Warburg effect was observed by treating PBMCs with PDAC-derived Exo: BXPC3 Exo induced a higher glucose consumption and lactate production than BxPC3-SMAD4+ Exo. Conclusion: PDAC-derived Exo from cells with, but mainly from those without SMAD4 expression, create an immunosuppressive myeloid cell background by increasing calcium fluxes and glycolysis through the transfer of SMAD4-related differentially expressed miRNAs and proteins. 


\section{INTRODUCTION}

Pancreatic ductal adenocarcinoma (PDAC) is still one of the most lethal forms of cancer worldwide despite the accumulating knowledge gained on its biology and genetics [1-3]. Recent studies exploring the whole genome and exome sequences revealed that the genetic landscape of PDAC is much more complex than previously believed, but they also confirmed that activating mutations of $K R A S$ and inactivating mutations in the tumor suppressor genes p53,CDKN2A and SMAD4 characterize this tumor type $[4,5]$. The loss of SMAD4, an almost unique event in gastrointestinal malignancies (e.g. colorectal adenocarcinoma), which occurs in about $50 \%$ of PDAC [2], appears to be of particular interest. PDAC patients carrying SMAD4 loss have a worse prognosis [6,7], and this event, in vitro, favors cell proliferation and migration, while antagonizing cell senescence [8]. It is widely believed that the molecular basis linking SMAD4 loss with increased tumor growth and aggressiveness depends on the absence of Smad4 protein, which mediates the effects of the transforming growth factor (TGF)- $\beta$ and bone morphogenetic protein, which inhibit cell proliferation and migration, and trigger apoptosis [9]. Yet this underlying mechanism cannot alone explain all PDAC features associated with SMAD4 loss, as recently demonstrated by Whittle et al. [10], who found that heterozygous SMAD4 mutation is associated with increased cellular proliferation but attenuates the metastatic potential of PDAC, while the complete loss of SMAD4 restores metastatic competency by regulating the expression of the transcription factor Runx3. Moreover, SMAD4 loss might underlie a more aggressive tumor pattern not only because tumor cells acquire a pro-proliferative and pro-metastatic phenotype, but also because it might create a favorable soil for tumor growth and metastasis by conditioning the surrounding stroma $[11,12]$.

The PDAC microenvironment, characterized by a dense desmoplastic reaction driven mainly by pancreatic stellate cells and pancreatic cancer associated fibroblasts, include immune cells, which have an imbalance toward an immunosuppressive and protumorigenic phenotype $[13,14]$. Immunosuppressive $\mathrm{T}_{\text {reg }}$ lymphocytes, $\mathrm{M} 2$ polarized tumor associated macrophages (TAM) and myeloid derived suppressor cells (MDSCs) prevail over immune effector $\mathrm{CD}^{+} \mathrm{T}$ cells, dendritic cells (DCs) and $\mathrm{M} 1$ polarized TAM in the tumor microenvironment, in blood and in lymphoid organs in both PDAC animal models and humans [15-23]. The immune imbalance in PDAC is an evolving phenomenon, starting in the early phases of carcinogenesis (i.e. in PanINs), a specific chronology of distinct immune cells subsets derangement paralleling disease progression [24]. While lymphocyte lineage alterations with $\mathrm{T}_{\text {reg }}$ accumulation appear to occur early, alterations in myeloid lineage with MDSCs accumulation appear to occur later in PDAC [20].
Overall, PDAC-associated immune cell alterations concur in masking tumor cells from immune detection, thus favoring tumor progression. This observation is borne out by clinical data demonstrating the negative prognostic value of immunosuppressive cellular accumulation, and experimental research is now being conducted to establish whether therapeutic benefit might be gained by targeting immunosuppressive cells $[14,20]$.

Immune cell alterations at the tumor site, and in nearby and distant organs, appear to depend on tumorderived and immunomodulatory molecules, including GM-CSF, S100A8/A9 heterocomplex and chemokines, which target the Ras/MAPK, Jak/Stat, PI3K and TGF $\beta$ pathways $[14,25]$. Soluble mediators, however, are not the only means of 'communication' between tumor cells and the surrounding stromal cells, extracellular micro vesicles also being involved [26]. Exosomes (Exo), defined as micro vesicles with a diameter ranging from 30 to 150 $\mathrm{nm}$, are released by cells and can transfer from one cell to another a rich cargo of molecular messengers, including miRNAs, proteins, lipids and DNA, which remains highly stable within the Exo shuttle [27]. The role of Exo has been highlighted in carcinogenesis, metastases, drug resistance and immunosuppression [28-31]. Among the mechanisms activated by cancer derived Exo in the specific immune cellular setting, Stat3 and NF-кB activation has been suggested to occur in a TLR-dependent fashion due to Hsp70, miR- 203 or as yet unidentified proteins [32, 33].

When investigating the immune cell response to cancer, the role of calcium signaling should be taken into account, since it plays a relevant role in the elaboration of the adaptive immune response thought to be crucial to cancer control $[34,35]$. It remains to be elucidated whether and, if so, how variations in the mutational landscape of PDAC, with a special focus on SMAD4 deletion, accelerates immunosuppression; this would lead to a greater understanding leading to new therapeutic targeting. In the present study we demonstrate that PDAC derived Exo imbalance immature myeloid cells subsets, enhancing MDSCs while lowering DCs, by altering intracellular calcium fluxes, these effects being magnified in cases of SMAD4 loss. The characterization of miRNAs, and the protein cargo of PDAC derived Exo, allowed us to discover SMAD4-associated de-regulated miRNAs and proteins, and to identify, among the more extensively de-regulated miRNA, hsa-miR-494-3p and hsa-miR-1260a, and among proteins, VDAC1 and spectrin beta, all involved in calcium balance. Finally, SMAD4 loss determined enrichment in the Exo protein cargo of glycolytic enzymes, these Exo being able to enhance myeloid cell glycolysis. 


\section{RESULTS}

\section{PDAC-derived Exo change the balance between MDSCs and DCs}

To ascertain whether pancreatic cancer cells modify the equilibrium between immunosuppressive and immune effector cells in an SMAD4-dependent manner and whether any imbalance is mediated by soluble factors or Exo, PBMCs were cultured for four days in complete, Exo enriched and Exo free non conditioned (NC) and conditioned media $(\mathrm{CM})$ obtained from BxPC3 and BxPC3-SMAD4+ cells. T cells and immature myeloid cells subsets were analyzed by flow cytometry and data from eight donors were collected. Only complete $\mathrm{CM}$ obtained from BxPC3-SMAD4+ cells caused a mild but significant expansion of $\mathrm{CD} 4{ }^{+} \mathrm{CD} 25^{+}$(Repeated measures ANOVA: $\mathrm{F}=10.77, p=0.003)$, while reducing $\mathrm{CD} 8^{+} \mathrm{T}$ cells $(\mathrm{F}=$ $8.348, p=0.007$ ) (Supplementary Figure 1).

Within the CD11b expressing immature myeloid cells, four subsets were identified on the basis of the expression of CD14 and HLA-DR markers: monocytes $\left(\mathrm{CD} 14^{+} \mathrm{DR}^{+}\right)$, DCs $\left(\mathrm{CD} 14-\mathrm{DR}^{+}\right)$, granulocytic (gMDSCs, CD14-DR-) and monocytic (mMDSCs, CD14 ${ }^{+} \mathrm{DR}^{-}$) MDSCs. Figure 1 shows a typical example of CD11b gating and the subsequent analysis of $\mathrm{CD} 11 \mathrm{~b}^{+}$cells on the basis of CD14 and HLA-DR expression (upper panels). Complete and Exo free $\mathrm{CM}$ obtained from both $\mathrm{BxPC} 3$ and BxPC3-SMAD4+ cells induced a significant increase

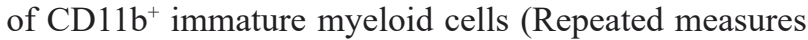
ANOVA: $\mathrm{F}=11.190, p=0.007$ and $\mathrm{F}=15.540, p=0.001$ respectively), while Exo enriched fraction did not (F $=0.102, p=0.793)$ (Figure 1, bottom panels). Cellular apoptosis (Annexin V) was not affected by any BxPC3 and BxPC3-SMAD4+ CM (Supplementary Table 1).

Figure 2 illustrates the distribution of the four myeloid cells subsets obtained in the above-described experimental conditions. Complete $\mathrm{CM}$ obtained from both $\mathrm{BxPC} 3-S M A D 4+$ and $\mathrm{BxPC} 3$ cells caused a significant increase in the percentage of mMDSCs (Repeated measures ANOVA: $\mathrm{F}=12.50, p=0.006$ ) while reducing both DCs $(\mathrm{F}=12.82, p=0.009)$ and gMDSCs $(\mathrm{F}=10.590, p=0.013)$. Exo enriched media enhanced the percentage of mMDSCs $(\mathrm{F}=3.749, p=0.059)$ but also gMDSCs $(\mathrm{F}=6.027, p=0.034)$ in a SMAD4 independent manner, while Exo free media reduced the DCs population in the presence of SMAD4 $(\mathrm{F}=7.711, p=0.014)$. The $\mathrm{CD} 11 \mathrm{~b}^{+} \mathrm{CD} 14-\mathrm{DR}^{+}$subset was confirmed to represent the DCs subpopulation in a separate series of two independent flow cytometry experiments with the CD80 and CD86 markers, which expression was not altered by $\mathrm{BxPC} 3$ or BxPC3-SMAD4+ CM (Supplementary Figure 2). Macrophages, classified as $\mathrm{CD} 11 \mathrm{~b}^{+} \mathrm{CD} 16^{+}$cells, were mainly allocated within the monocytes subset and in part in the mMDSCs subset, and they were not affected by treatment with cancer conditioned complete, Exo enriched and Exo free media (Supplementary Table 2).

The data obtained indicate that PDAC cells induce the expansion of $\mathrm{CD}_{11 \mathrm{~b}^{+}}$immature myeloid cells in a SMAD4-independent manner through the release of soluble mediators. Within this expanded population of myeloid cells, PDAC through off balance between immature myeloid cells subsets, lowering DCs and gMDSCs, while enhancing mMDSCs, whether in the absence or presence of SMAD4 gene expression. Exo from BxPC3 appear to mediate the expansion of any immunosuppressive cell subtype.

\section{PDAC lowers TNF release by PBMCs in a SMAD4-dependent manner}

IL-1 $\beta$, IL-4, IL-6, IL-10, TGF- $\beta 1$ and TNF were assayed in PBMCs' supernatants before and after four days in NC and in CM. IL-1 $\beta$, IL-4, IL-6, IL10 did not vary and levels were below the lower limit of detection in all conditions. The levels of TGF- $\beta 1$ measured in PBMCs supernatants collected after four days of culture did not significantly vary between $\mathrm{NC}(5,18 \pm 0,46$ $\mu \mathrm{g} / \mathrm{L}$, mean \pm SEM from 4 replicated experiments), BxPC3 $\mathrm{CM}(5,25 \pm 0,74 \mu \mathrm{g} / \mathrm{L})$ and BxPC3-SMAD4+ $\mathrm{CM}(4,89 \pm 0,40 \mu \mathrm{g} / \mathrm{L})($ One-way Anova: $\mathrm{F}=0.465, p=$ $0.556)$. With respect to basal levels, a significant increase of TNF was found in NC PBMCs after four days of culture (from $4.81 \pm 0.16 \mathrm{pg} / \mathrm{mL}$ to $265.4 \pm 94.9 \mathrm{pg} / \mathrm{mL}$, mean \pm SEM from 19 donors; Student's $t$ test for paired data: $\mathrm{t}=2.755, p=0.013$ ). The levels of TNF measured in PBMCs supernatants after four days in BxPC3 and BxPC3-SMAD4+ CM were expressed as percentage with respect to the corresponding TNF levels of NC PBMCs considering any donor of this series of 19 donors. The results are shown in Supplementary Table 3, which also reports the results obtained in a subset of 12/19 donors, for which parallel experiments were performed using Exo enriched $\mathrm{NC}$ and $\mathrm{CM}$. With respect to $\mathrm{NC}$ media, the release of TNF by PBMCs was reduced by BxPC3$S M A D 4+\mathrm{CM}$, but mainly by BxPC3 CM. Exo enriched media did not reproduce the inhibitory effect observed with the employment of complete media.

\section{PDAC-derived Exo increase intracellular calcium fluxes in a SMAD4 dependent manner}

With the aim to verify whether $\mathrm{Ca}^{2+}$ ions were involved in the observed PDAC dependent changes in myeloid cell subsets and TNF secretion, $\left[\mathrm{Ca}^{2+}\right]_{\mathrm{i}}$ fluxes were studied in PBMCs treated in the same conditions described above and Figure 3 shows the results of representative experiments for any studied condition each reporting results from 8 cells. Minimal and irregular variations in 
$\left[\mathrm{Ca}^{2+}\right]_{\mathrm{i}}$ were observed in NC complete and Exo-enriched media (Figure 3, upper panels), while an increased frequency of $\left[\mathrm{Ca}^{2+}\right]_{\mathrm{i}}$ was observed in PBMCs cultured in BxPC3-SMAD4+, but mainly in BxPC3 complete CM, the results being reproduced by Exo-enriched CM. To compare the results, we classified variations in $\left[\mathrm{Ca}^{2+}\right]_{\mathrm{i}}$ as absent or present and, in this latter case, as regular peaks or irregular oscillations. In each experiment the number of cells belonging to the first (stable $\left[\mathrm{Ca}^{2+}\right]_{\mathrm{i}}$ ), second (peak $\left[\mathrm{Ca}^{2+}\right]_{\mathrm{i}}$ ) or third group (irregular $\left[\mathrm{Ca}^{2+}\right]_{\mathrm{j}}$ ) were counted. BxPC3-SMAD4+, but mainly BxPC3 complete CM caused a significant increase in the number of cells with a peak or irregular behavior of $\left[\mathrm{Ca}^{2+}\right]_{\mathrm{i}}\left(\mathrm{X}^{2}=13.480, p=0.009\right)$ and this finding was confirmed when cells were incubated with Exo-enriched CM $\left(\mathrm{X}^{2}=14.212, p=0.007\right)$. In the bottom panel of Figure 3 the percentages of PBMCs showing an irregular or a peak $\left[\mathrm{Ca}^{2+}\right]_{\mathrm{i}}$ pattern after they have been incubated in complete or Exo enriched $\mathrm{NC}$ or pancreatic cancer CM are shown.

\section{DCs do not pulse whereas regular intracellular calcium fluxes characterize mMDSCs}

To verify whether any specific pattern of $\left[\mathrm{Ca}^{2+}\right]_{i}$ was correlated with any specific myeloid cell subset, PBMCs from 3 donors were incubated with BxPC3-SMAD4+ CM for 96 hours to enrich the immunosuppressive populations before performing FACS sorting. Monocytes, DCs, gMDSCs and mMDSCs were collected, seeded, and cultured in NC media for 48 hours before $\left[\mathrm{Ca}^{2+}\right]_{\mathrm{i}}$ analysis. Figure 4 shows $\left[\mathrm{Ca}^{2+}\right]_{\mathrm{i}}$ in the four myeloid cellular subsets. Monocytes had both peaks and irregular $\left[\mathrm{Ca}^{2+}\right]_{i}$ whereas DCs did not pulse. FACS sorted gMDSCs hardly adhered to coverslips glass slides and only two records were available, but both cells had a stable profile. Conversely mMDSCs were characterized by the presence of well defined regular peaks and by the absence of irregular $\left[\mathrm{Ca}^{2+}\right]_{\mathrm{i}}$. FACS sorted gMDSCs and mMDSCs were stained with May-Grünwald-Giemsa (Figure 4, bottom panels).

\section{The SMAD4-dependent Exo miRNAs 494-3p and 1260a induce intracellular calcium fluxes in PBMCs}

According to the microarray analysis, the heat map of the differentially expressed miRNAs was generated by unsupervised hierarchical clustering analysis (Figure 5). The most deregulated 30 miRNAs, detected by highest absolute value of logarithmized estimated fold change, are reported in Supplementary Table 4. Microarray data were validated using real time PCR, analyzing two of the most de-regulated miRNAs, hsa-miR-494-3p and hsamiR-1260a. The Ct of three experimental replicates, each run in duplicate, obtained in $\mathrm{BxPC} 3$ derived Exo ranged from 30.93 to 31.91 for hsa-miR-494-3p and from 27.81 to
27.85 for hsa-miR-1260a. After normalization to U6 small RNA Exo content, the relative expression of any miRNA in BxPC3-SMAD4+ derived Exo was referred to that of BxPC3. It was confirmed that hsa-miR-494-3p was under expressed (relative quantification $=0.8 \pm 0.0$, mean $\pm \mathrm{SD}$ ), while hsa-miR-1260a was over expressed (1.2 \pm 0.0$)$ in $\mathrm{BxPC} 3-S M A D 4+$ with respect to $\mathrm{BxPC} 3$ derived Exo. To ascertain whether the differential expression of these two miRNAs was correlated with variations in calcium fluxes of myeloid cells, transfection induced expression and inhibition of hsa-miR-494-3p and of hsamiR-1260a in both BxPC3 and BxPC3-SMAD4+ cells were performed. PBMCs were maintained in complete $\mathrm{CM}$ obtained from non transfected and transfected or inhibited pancreatic cancer cells. Figure 6 shows $\left[\mathrm{Ca}^{2+}\right]_{i}$ of representative hsa-miR-494-3p and of hsa-miR-1260a transfection experiments, while Supplementary Figure 3 shows the corresponding findings with inhibition experiments. The induced expression of hsa-miR-494-3p in both pancreatic cancer cell lines and of hsa-miR-1260a in BxPC3-SMAD4+ cells determined in PBMCs a similar and progressive increase of $\left[\mathrm{Ca}^{2+}\right]_{i}$. The magnitude of 10 minutes increment was calculated for any individual cell in all experimental conditions, being mean values confirmed to be significantly enhanced by hsa-miR-494$3 p$ (Supplementary Figure 4, upper panels). hsa-miR1260 a caused a similar increment only when expressed by $\mathrm{BxPC} 3$. The expression or inhibition of these two miRNAs by BxPC3 did not affect the number of PBMCs with a peak behavior of $\left[\mathrm{Ca}^{2+}\right]_{\mathrm{i}}$ (Supplementary Figure 4, lower left panel). By contrast hsa-miR-1260a expression in BxPC3-SMAD4+ induced a significant increase in the percentage of PBMCs with regular calcium peaks (Supplementary Figure 4, lower right panel), and favored PBMCs to form clusters (Supplementary Figure 5).

\section{SMAD4 loss determines enrichment in Exo proteins of the glycolysis biological process}

The differentially expressed proteins between BxPC3-SMAD4+ and BxPC3 derived Exo, evaluated by SILAC experiments, were defined as proteins with a ratio between heavy (BxPC3) and light (BxPC3-SMAD4+) isoforms below 0.667 and above 1.5 , respectively. The identified proteins with a ratio below 0.667 were those under-expressed, while those with a ratio above 1.5 were over-expressed in $\mathrm{BxPC} 3$ with respect to $\mathrm{BxPC} 3-$ SMAD4+ Exo. Supplementary Table 5 reports the Uniprot accession number, protein description, and heavy/light ratio of the SMAD4-related differentially expressed proteins in tumor-derived Exo. Using David software, a comprehensive analysis was made of differentially expressed proteins between BxPC3 and BxPC3-SMAD4+ derived Exo. The GO-terms for biological processes found to be significant after Benjamini and Hochberg adjustment 
for multiple comparisons were selected (Supplementary Figure 6). Eleven biological processes were identified, including translation, cell adhesion, cell signaling and glycolysis. Focusing on glycolysis, we found that BxPC3 cells had a higher degree of glucose consumption and of lactate production than BxPC3-SMAD4+ cells (Figure 7, upper left panel). To verify whether the different expression of glycolytic enzymes between BxPC3 and BxPC3-SMAD4+ derived Exo had an impact on glucose metabolism of myeloid cells, glucose and lactate were assayed in the supernatants of PBMCs cultured for 2, 24, 48, 72 and 96 hours in Exo-enriched $\mathrm{CM}$ and $\mathrm{NC}$ media, the results from three independent experiments each made in duplicate being shown in the right panels of Figure 7. BxPC3, not BxPC3-SMAD4+, Exo enriched media induced significantly greater glucose consumption and lactate production with respect to Exo enriched NC media. To verify whether PDAC-derived Exo transfer the glycolytic enzymes into PBMCs, the activity of $\mathrm{LDH}$, one of the most differentially expressed proteins between BxPC3 and BxPC3-SMAD4+ derived Exo, was assayed in PBMCs after they have been cultured for 24 hours in $\mathrm{NC}$ and in serially diluted BxPC3 Exo-enriched CM. $\mathrm{LDH}$ activity in PBMCs increased in the presence of Exo with respect to $\mathrm{NC}$ (Figure 8, upper panel: $\mathrm{F}=7.777, p$ $=0.0093$ from three independent experiments). Similarly, the expression levels of hsa-miR-494-3p were increased in PBMCs after they have been treated with BxPC3 Exo enriched CM, although differences were not statistically significant (Figure 8, lower panel: $\mathrm{F}=0.568, p=0.665$ ). Transfection induced expression of hsa-miR-1260a, not of hsa-miR-494-3p, reduced glucose consumption and lactate production in BxPC3-SMAD4+ cells $(\mathrm{F}=4.253, P=0.009$ and $\mathrm{F}=4.751, p=0.006)$.

\section{DISCUSSION}

Alterations in genetic and epigenetic, transcription

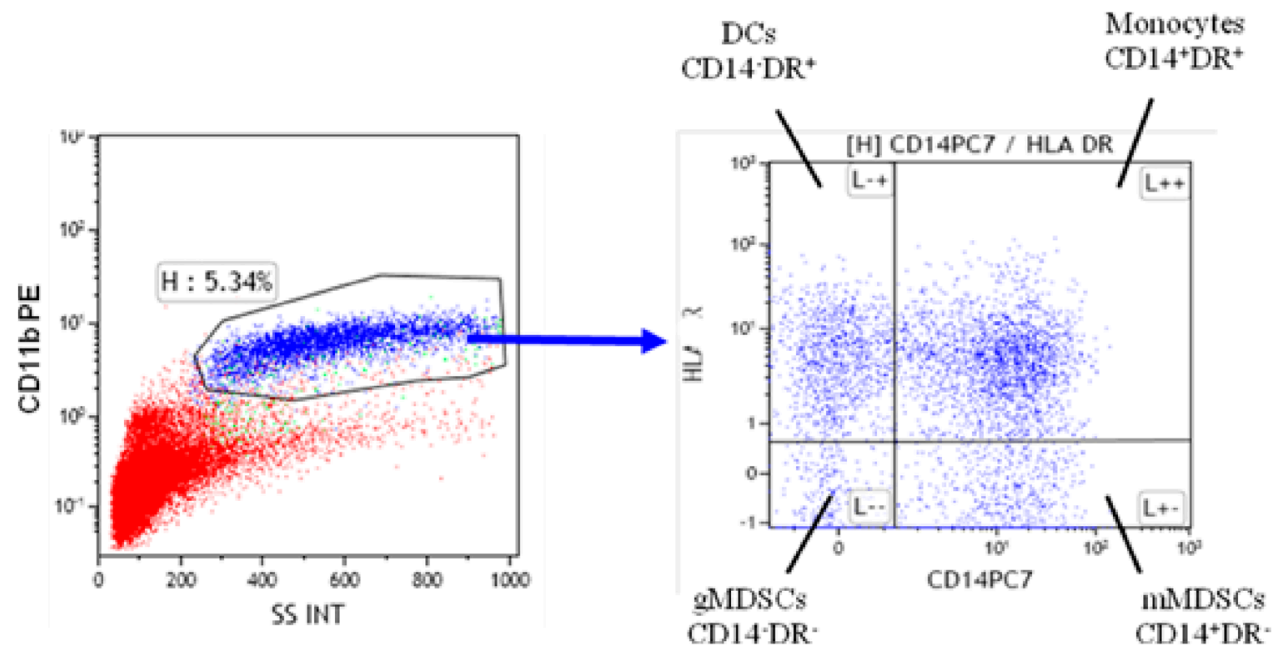

Complete media

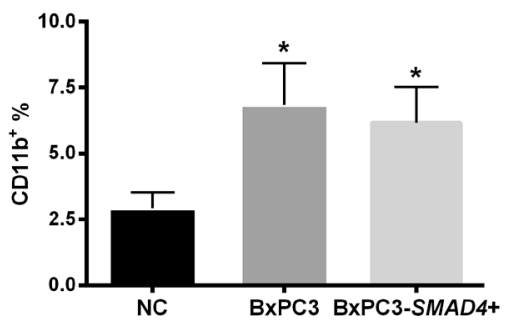

Exo free media

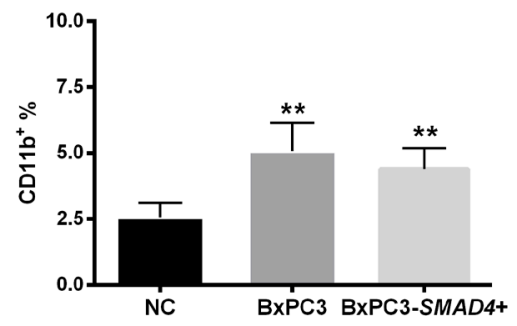

Exo enriched media

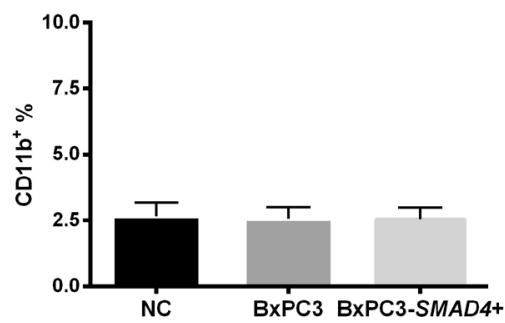

Figure 1: BxPC3 and BxPC3-SMAD4+ CM expand CD11 $\mathrm{b}^{+}$immature myeloid cells. Upper panels: Representative CD11b gating in flow cytometry (upper left panel) and subsequent analysis of CD11 ${ }^{+}$cells on the basis of CD14 and HLA-DR expression (upper

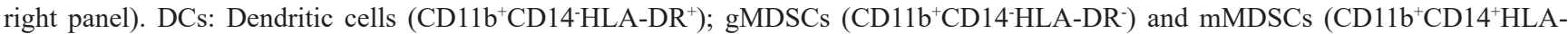

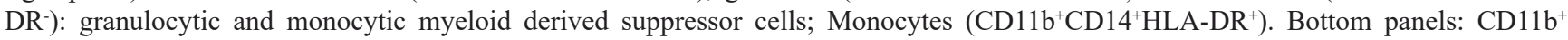
immature myeloid cells counted after incubating PBMCs for four days with complete, Exo free and Exo enriched BxPC3 (dark grey columns) or BxPC3-SMAD4+ (light grey columns) conditioned media. PBMCs were always run in parallel in complete, Exo free and Exo enriched non-conditioned medium (NC, black columns). All data are given as average values $\pm \mathrm{SEM}$ obtained for 8 donors $*=p<0.05$ and $* *=p<0.01$ with respect to NC (Tukey's multiple comparisons test). 
and signaling programs converge and concur in determining PDAC, a tumor expected to become the second most common cause of cancer-related mortality in 2030 in the absence of advances in therapy [36]. A relevant co-determinant in PDAC progression is the immunosuppressive ground associated with this tumor type [3]. In order to gain a deeper understanding of the complexity of immunoregulation in PDAC, in this study we provide evidence that SMAD4 loss imbalances immature myeloid cellular subsets in favor of MDSCs by altering intracellular calcium doing this through miRNAs and proteins Exo transfer from cancer cells to myeloid cells.

We first observed that, in the presence of PDAC CM, T cells subsets were unbalanced towards immunosuppression: $\mathrm{CD}^{+} \mathrm{T}$ immunoeffector cells were
Complete media
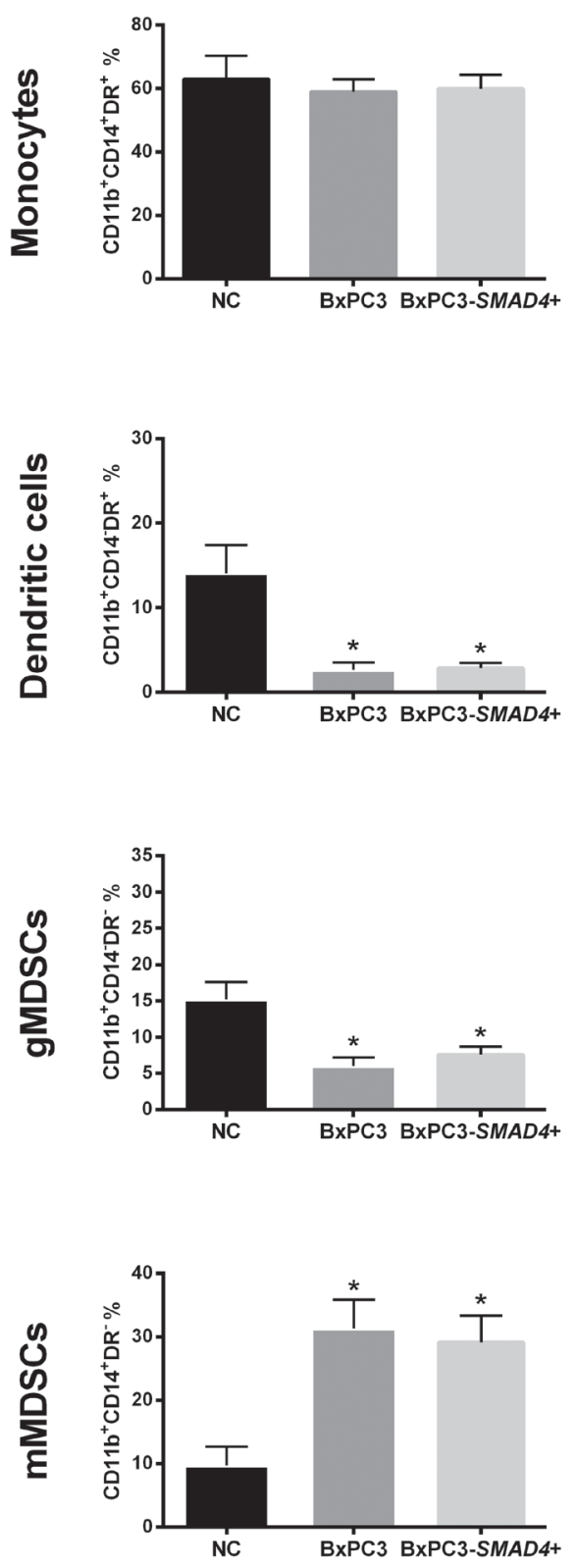

Exo free media
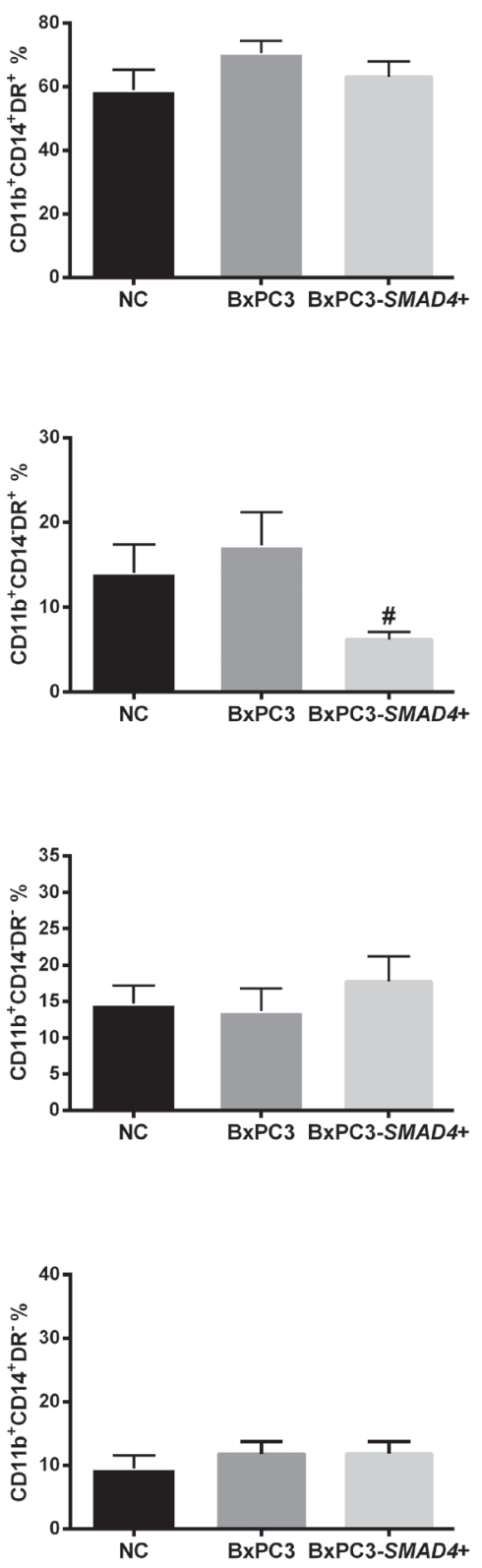

\section{Exo enriched media}
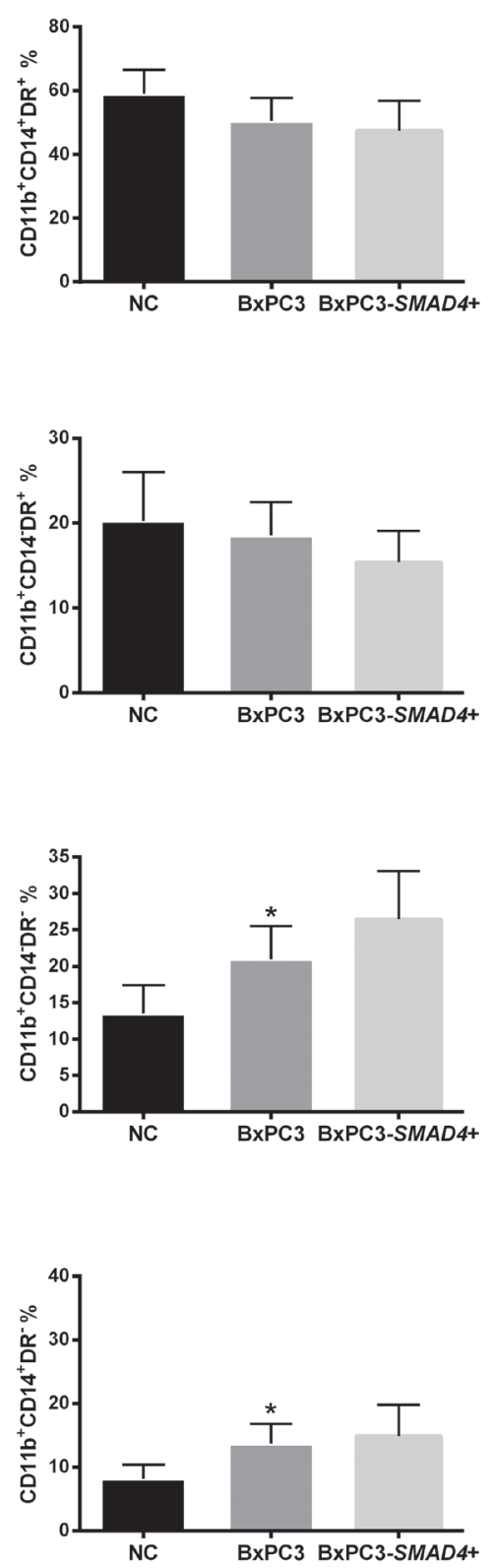

Figure 2: BxPC3 derived Exo expand myeloid derived suppressor cells. Monocytes, dendritic cells, granulocytic and monocytic derived suppressor cells (gMDSCs and mMDSCs) were counted after PBMCs were incubated for four days with complete, Exo free and Exo enriched BxPC3 (dark grey columns) or BxPC3-SMAD4+ (light grey columns) conditioned media (CM). PBMCs were always run in parallel in complete, Exo free and Exo enriched non-conditioned medium (NC, black columns). All data are given as the average values \pm SEM obtained from eight donors $*=p<0.05$ with respect to $\mathrm{NC}$ and $\#=p<0.05$ with respect to NC and BxPC3 (Tukey's multiple comparisons test). 
Complete media
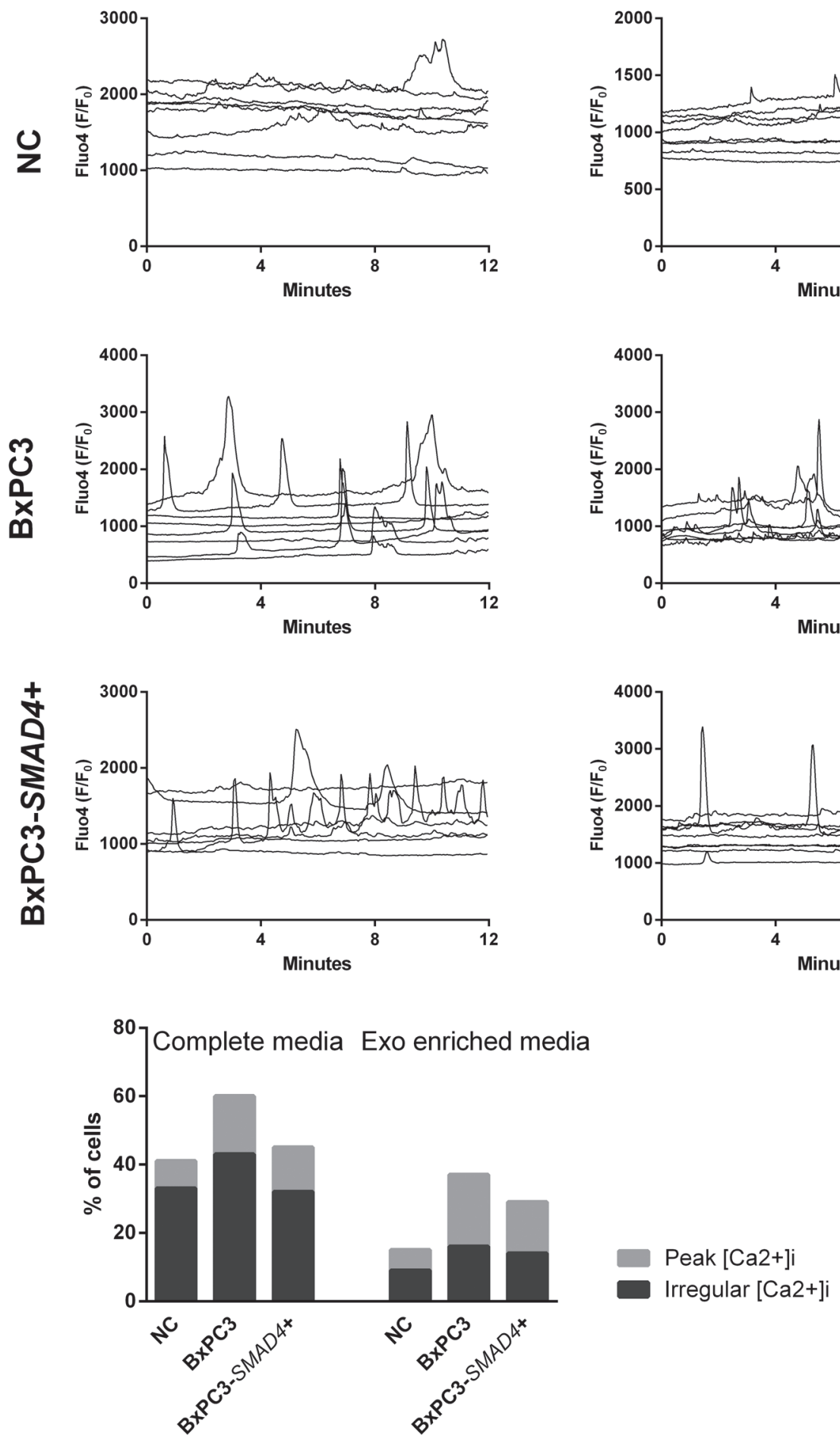

\section{Exo enriched media}
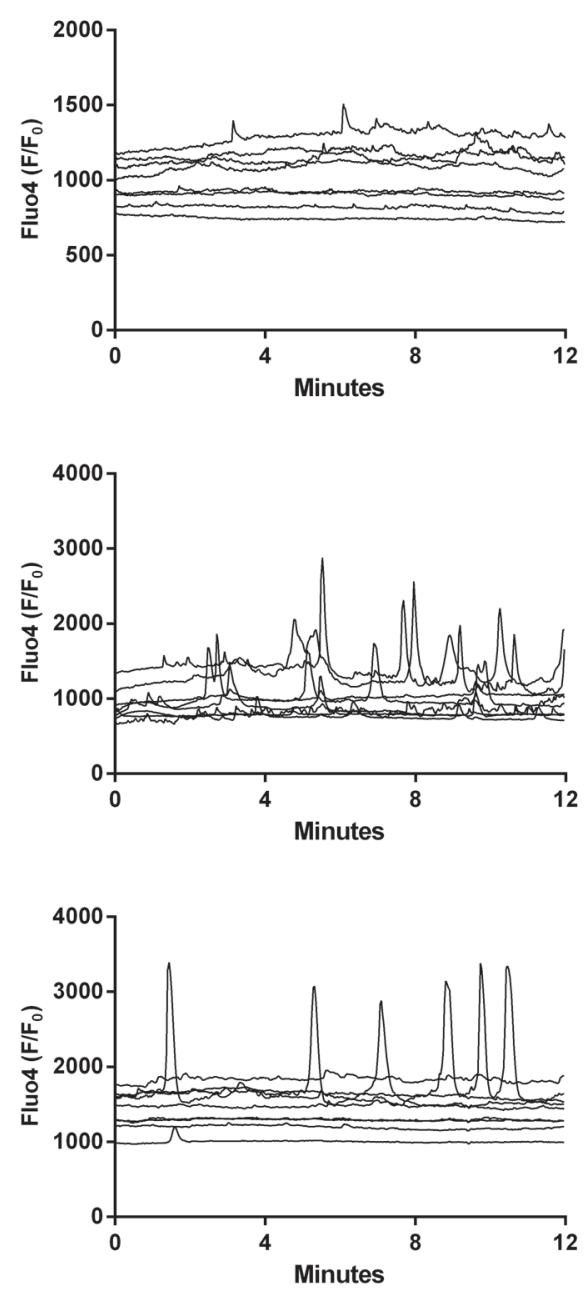

Peak $[\mathrm{Ca} 2+] \mathrm{i}$

Irregular $[\mathrm{Ca} 2+] \mathrm{i}$

Figure 3: Intracellular calcium fluxes $\left(\left[\mathbf{C a}^{2+}\right]_{i}\right)$ of PBMCs. The variations in $\left[\mathrm{Ca}^{2+}\right]_{i}$ after incubation for 72 hours in complete or Exo enriched non conditioned (NC) or BxPC3 and BxPC3-SMAD4+ conditioned media are shown as Fluo4 F/ $\mathrm{F}_{0}$ ratio. Each graph represents one experiment and each line $\left[\mathrm{Ca}^{2+}\right]_{\mathrm{i}}$ of one cell. The bottom graph shows the percentages of PBMCs that peak (clear grey bars) or have an irregular $\left[\mathrm{Ca}^{2+}\right]_{\mathrm{i}}$ (dark grey bars) after 72 hours' incubation in complete or Exo enriched NC or conditioned media. Totals of 162, 129 and 164 cell data were obtained from 12 independent experiments for the entire $\mathrm{NC}, \mathrm{BxPC} 3 \mathrm{CM}$ and $\mathrm{BxPC} 3-S M A D 4+\mathrm{CM}$, respectively. Totals of 108, 130 and 126 cell data were obtained from 9 independent experiments for Exo-enriched NC , BxPC3 CM and BxPC3-SMAD4+ CM, respectively. 
reduced while $\mathrm{CD} 4{ }^{+} \mathrm{CD} 25^{+}$cells underwent expansion. These "in vitro" results are is in agreement with the decreased $\mathrm{CD}^{+}$and increased $\mathrm{CD}^{+} \mathrm{CD} 25^{+} \mathrm{Foxp}^{+}{ }^{+} \mathrm{T}$ cell stromal infiltration found in human tumors, and described to be associated with shorter survival [18, 37]. Interestingly, these PDAC-driven effects on T cells were SMAD4-dependent, being observed when BxPC3 cells

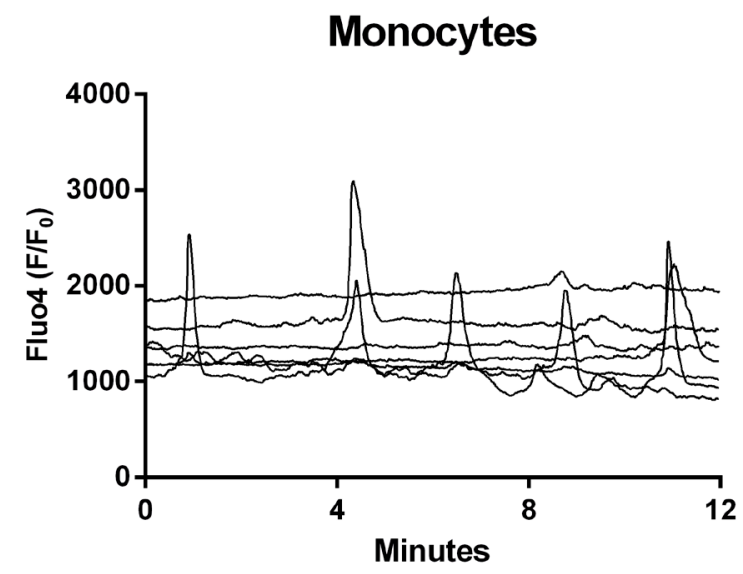

mMDSCs
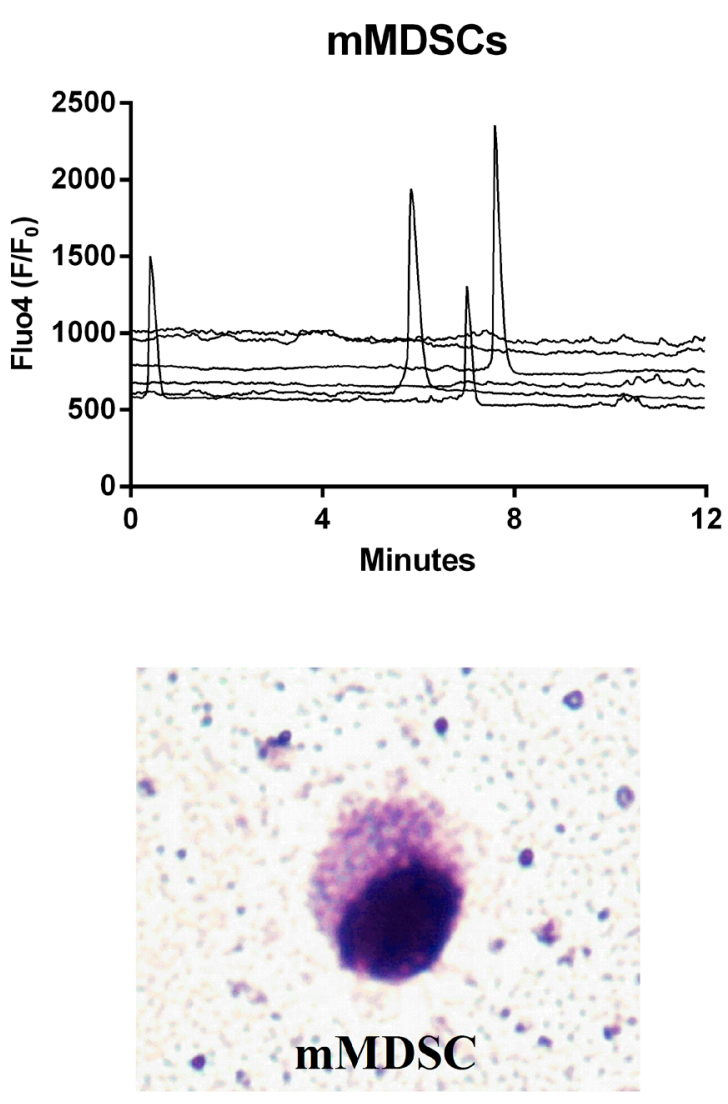

were forced to express SMAD4. The immunosuppressive T cell phenotype induced by PDAC CM might be mediated by soluble factors but also by factors carried in Exo, currently considered an important route for cell to cell communication [32, 38-40]. Both the soluble fraction and the Exo enriched fractions of PDAC CM failed to reproduce the effects on $\mathrm{T}$ cells evoked by complete
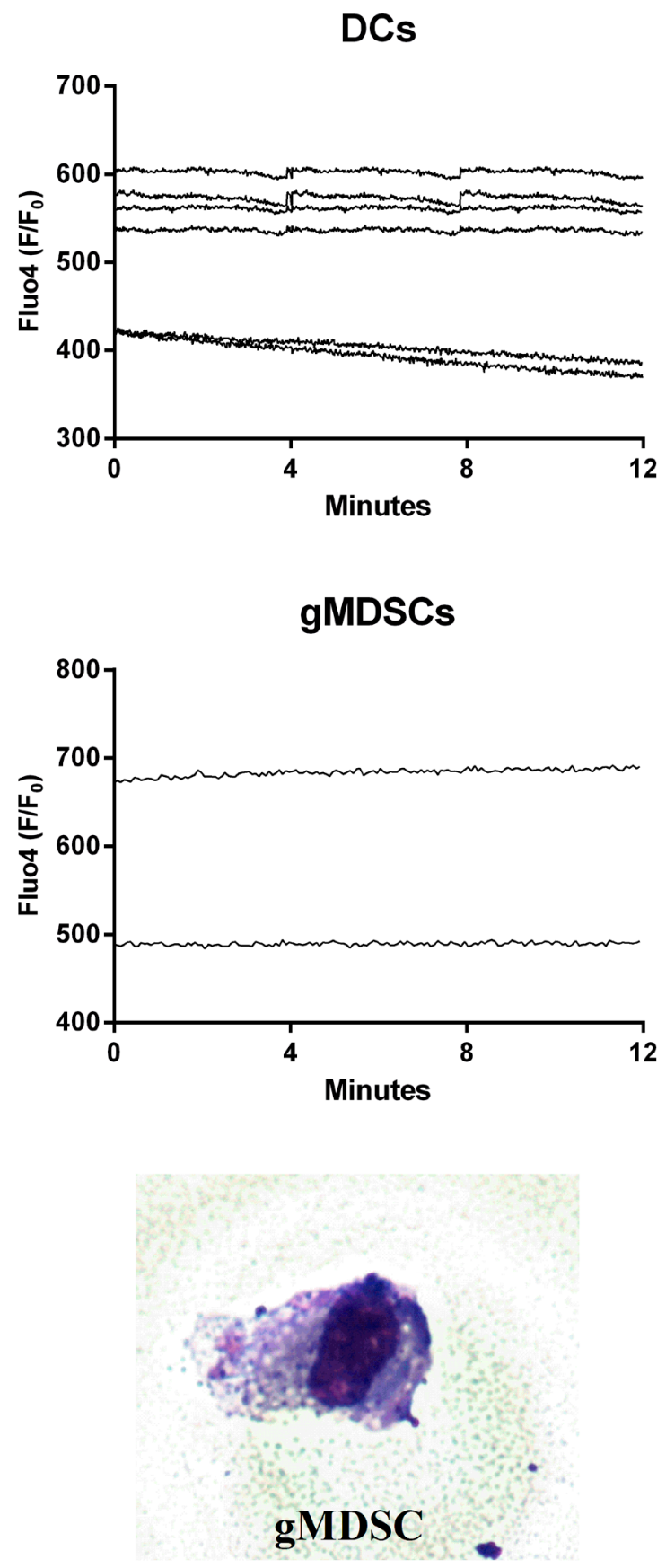

Figure 4: Intracellular calcium fluxes $\left(\left[\mathrm{Ca}^{2+}\right]\right.$ i) of FACS sorted immature myeloid cell subsets. The variations in $\left[\mathrm{Ca}^{2+}\right]_{\mathrm{i}}$ of each cellular subset after sorting and incubation for 48 hours in non conditioned media are shown as Fluo $4 \mathrm{~F} / \mathrm{F}_{0}$ ratio. Each graph represents one experiment and each line, the $\left[\mathrm{Ca}^{2+}\right]_{i}$ of one cell. The bottom images show FACS sorted gMDSC cell (right) and mMDSC cell (left) at light microscopy $(50 \times)$ after May-Grünwald-Giemsa staining. The percentage of Annexin V+ cells (Flow cytometry) after 18 hours from sorting was $79 \%$ among monocytes, $69 \%$ among DCs, $67 \%$ among gMDSCs and $70 \%$ among mMDSCs. 
media. This might alternatively or additionally depend on: 1. co-operation between soluble factors and Exo being required to alter $\mathrm{T}$ cells phenotypes; 2 . magnitude of observed variations in T cells, subsets being too small to be reproduced by any single fraction. Moreover, PDACderived factors (e.g. GM-CSF) may directly trigger the variations observed in T cells phenotypes [20], but these variations are more likely to be secondarily induced by myeloid cells, a potential main target of PDAC-derived immunomodulatory factors [23, 41]. In line with this hypothesis, PDAC CM significantly altered myeloid cell subsets in a SMAD4 independent manner, causing the reduction of DCs and of their main cytokine, TNF, in favor of the induction of mMDSCs. gMDSCs, unlike mMDSCs, were inhibited by PDAC CM and this fits well with the hypothesized equilibrium between these two immunosuppressive myeloid cell populations, i.e. the expansion of one set being correlated with the inhibition of the other set [20]. Differently form complete media, Exo were able to induce the expansion of both mMDSC and gMDSC subsets, being these effects SMAD4 - related.

Since myeloid cells with an immunosuppressive

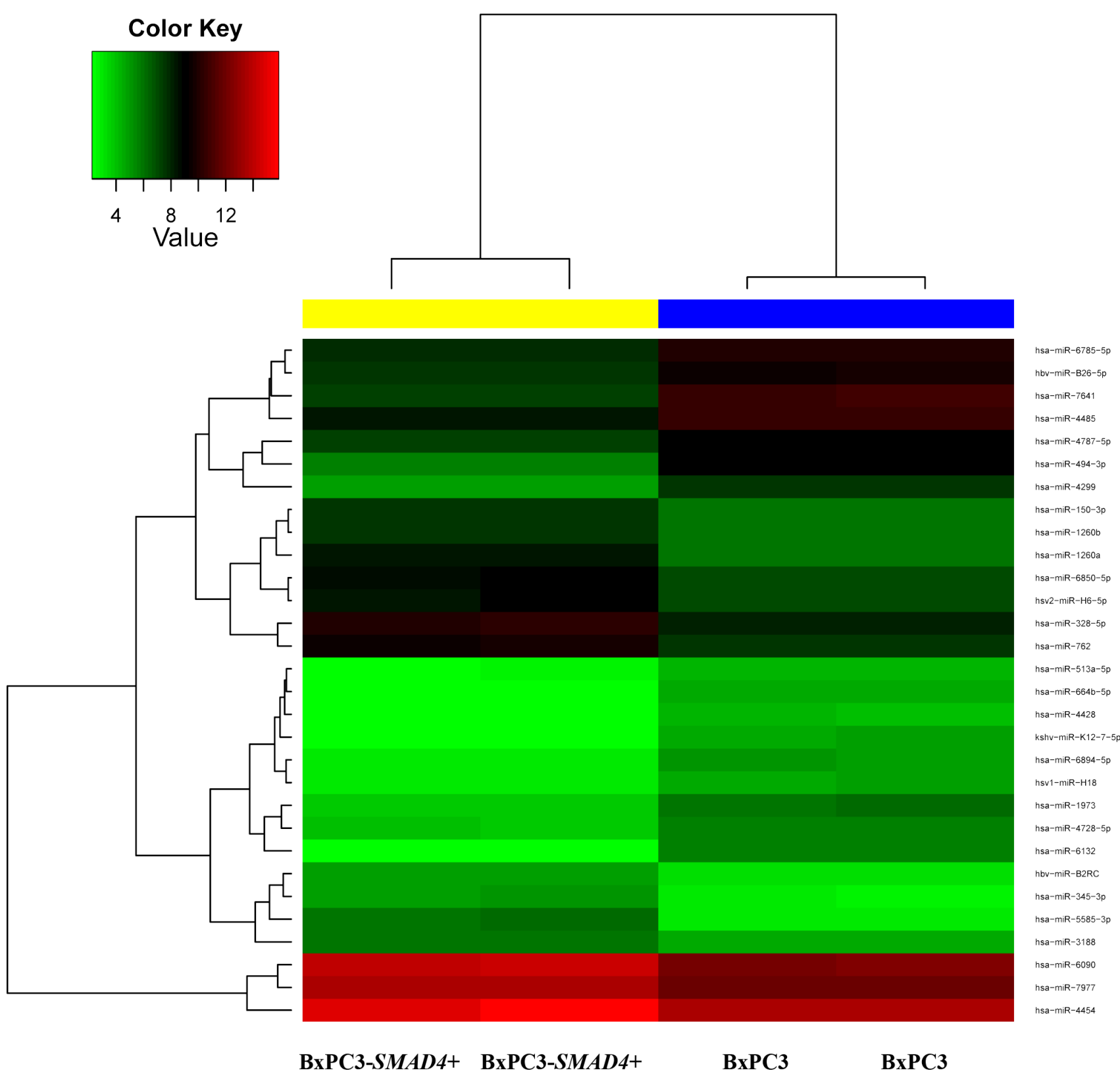

Figure 5: Heatmap for comparison between BxPC3-SMAD4+ and BxPC3 Exo miRNAs. The color of the horizontal side bar at the top of the plot indicates the group membership of a given sample (yellow: BxPC3-SMAD4+, two replicates; blue: BxPC3, two replicates). 
phenotype prevailed in PDAC CM, we verified whether immunosuppressive cytokines increased in this setting. IL-1 $\beta$, IL-4, IL-6 and IL10 were below the respective limits of detection, while TGF- $\beta 1$ increased in PBMCs culture media on the fourth day of culture ( 2 fold) [20, 41]. However, no significant differences were found between NC and PDAC conditioned PBMCs. This finding might not support the hypothesis that TGF- $\beta 1$ is associated with PDAC induced immunosuppression, but it might also be consequent to 1) the autocrine/ paracrine action of this cytokine, the amount produced being rapidly taken up by producing and/or adjacent cells thus limiting the cytokine quota released in culture media and 2) our results come from one particular cell line which definitively does not represent the whole complexity of PDAC immunosuppressive networtk. In this network macrophages should also be considered, because they might enhance tumor-initiating capacity and suppress $\mathrm{CD}^{+} \mathrm{T}$ cells when educated by tumor cells [19], although in our experimental model macrophages appeared unaffected. This finding per se does not contradict the established concept that in PDAC tissue TAM increase and concur in enhancing tumor progression and chemoresistance. Our experimental model allows to investigate the effects of tumor derived soluble products and Exo on peripheral blood mononuclear cells, the precursors of TAM, which complete differentiation requires a more intimate and complex contact of monocytes with tumor cells and other stromal cells [22].

PDAC CM and Exo in particular might induce the expansion of immunosuppressive myeloid cells by activating critical intracellular signaling pathways, mainly JAK/STAT kinase, TGF- $\beta$ and RAGE [25]. Calcium calmodulin is a critical pathway involved in many cellular functions, including myeloid cell differentiation $[35,42]$. Regular $\left[\mathrm{Ca}^{2+}\right]_{\mathrm{i}}$ pulses are required to maintain normal myeloid cellular function, and any disruption of this mechanism might underlie alterations in phenotype and function such as those observed in the present study [43]. This was the premise of our subsequent experiments conducted to evaluate $\left[\mathrm{Ca}^{2+}\right]_{\mathrm{i}}$ fluxes in the above described experimental settings. PBMCs cultured in NC medium showed irregular variations in $\left[\mathrm{Ca}^{2+}\right]_{\mathrm{i}}$ resembling background noise. A higher frequency of $\left[\mathrm{Ca}^{2+}\right]_{i}$ spikes were found in PBMCs cultured in BxPC3-SMAD4+, but mainly in $\mathrm{BxPC} 3$ complete $\mathrm{CM}$, and these variation were reproduced by Exo enriched media, suggesting that in case of SMAD4 loss cancer derived Exo magnify their ability to induce an increased calcium trafficking in PBMCs. $\mathrm{Ca}^{2+}$ responsible for this increased cellular activity might derive from the extra-cellular space and the intracellular stores [42]. We believe that both are involved, since after blocking membranal $\mathrm{Ca}^{2+}$ channels with verapamil, an overall reduction in $\left[\mathrm{Ca}^{2+}\right]_{\mathrm{i}}$ fluxes was observed but the difference between control and PDAC treated cells was maintained (data not shown). Since the variations in $\left[\mathrm{Ca}^{2+}\right]_{i}$ pattern mirrored those in myeloid cell phenotypes, we analyzed the $\left[\mathrm{Ca}^{2+}\right]_{\mathrm{i}}$ pattern of single cells populations after they have been FACS sorted, and demonstrated that DCs are static while mMDSCs present regular and well defined $\left[\mathrm{Ca}^{2+}\right]_{\mathrm{i}}$ peaks. Only few FACS sorted gMDSCs could be analyzed, since they did not adhere to the glass supports and this might be consequent to increased apoptosis of sorted cells in standard media for 48 hours, in agreement with Stromnes et al. [20]. These data support the notion that PDAC cells and, in particular, PDAC derived Exo reduce DCs and expand mMDSCs through $\left[\mathrm{Ca}^{2+}\right]_{\mathrm{i}}$ changes, this phenomenon being SMAD4-dependent. This is the first time that such a mechanism has been described in literature.

Among the potential causative agents responsible for this pathogenic mechanism, SMAD4-related differences in the amount of Exo release might be hypothesized, also considering that a dose-related effect of $\mathrm{BxPC} 3$ derived Exo in inducing gMDSCs was found (data not shown). However, the role of SMAD4-differentially expressed miRNAs and/or proteins carried in PDAC-derived Exo, which transfer their cargo from cancer cells to immune cells thus altering their behavior should also be taken into account. Therefore we screened the differentially expressed miRNAs and proteins in $\mathrm{BxPC} 3$ and $\mathrm{BxPC} 3-$ $S M A D 4+$ derived Exo by microarray analysis and SILAC respectively.

A number of miRNAs were found to be differentially expressed between Exo from the two cell lines studied. We selected two of the most SMAD4-associated de-regulated miRNAs, the hsa-miR-494-3p, which was previously demonstrated by Li et al. to be closely associated with SMAD4 expression [44], and hsa-miR-1260a, which association with SMAD4 is reported here for the first time. To ascertain whether these two miRNAs have any role in the calcium balance of myeloid cells, transfection and inhibition experiments were performed. In the absence of SMAD4 (BxPC3) the expression of both hsamiR-494-3p and hsa-miR-1260a caused a progressive accumulation in intracellular calcium in PBMCs. The expression of hsa-miR-1260a augmented the percentage of PBMCs with regular calcium peaks and induced cells to form large clusters only when SMAD4 was also expressed (BxPC3-SMAD4+), suggesting that these hsamiR-1260a-related effects require other cancer derived SMAD4-related co-factors, being SMAD4-related proteins potential candidates. The most de-regulated proteins between SMAD4 expressing and non expressing cellular derived Exo were mainly involved in translation, cell and matrix adhesion, integrin and Ras signaling, and this is in agreement with a more aggressive SMAD4-associated phenotype. Three proteins overexpressed in $\mathrm{BxPC} 3$ with respect to BxPC3-SMAD4+ derived Exo, appear of potential interest for further studies because of their known effects on immune cells and/or trans membrane ion fluxes: VDAC1, Versican and Spectrin beta [45, 46]. A number of 


\section{$\mathrm{BxPC3}$}

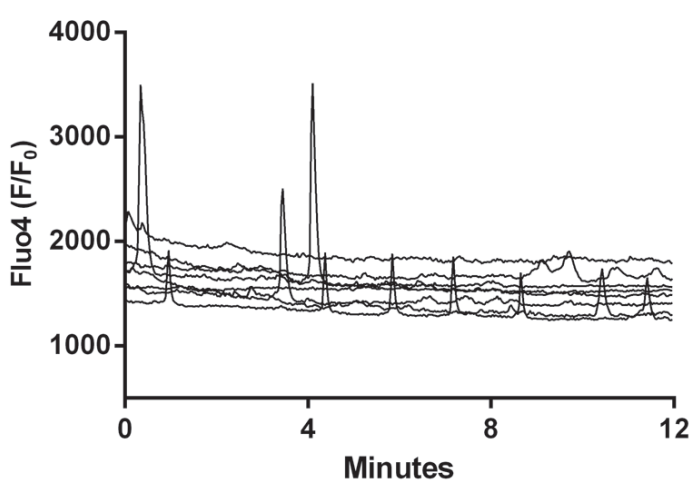

BxPC3 hsa-miR-494-3p

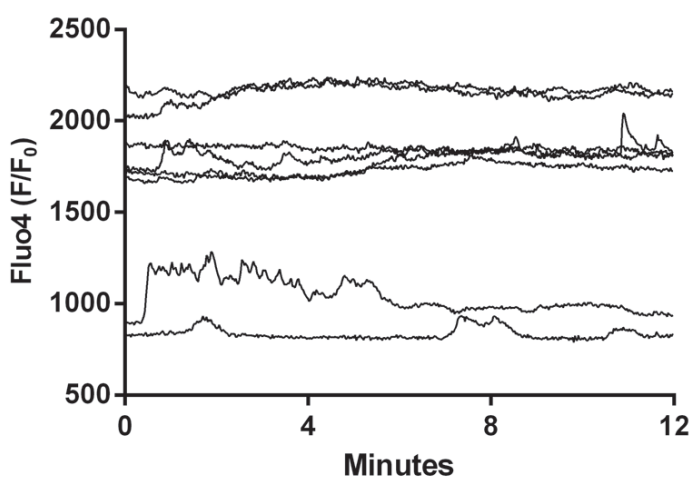

BxPC3 hsa-miR-1260a

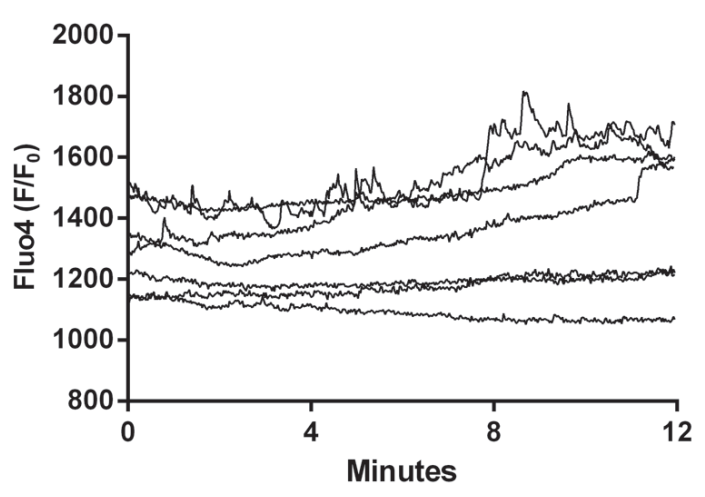

BXPC3-SMAD4+

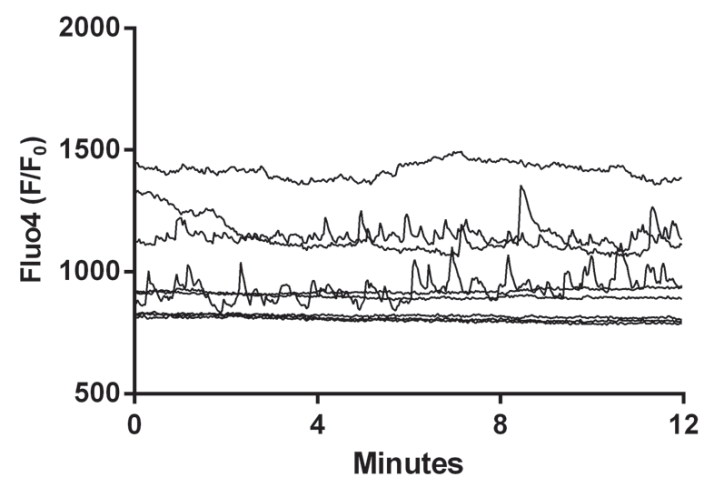

BxPC3-SMAD4+ hsa-miR-494-3p

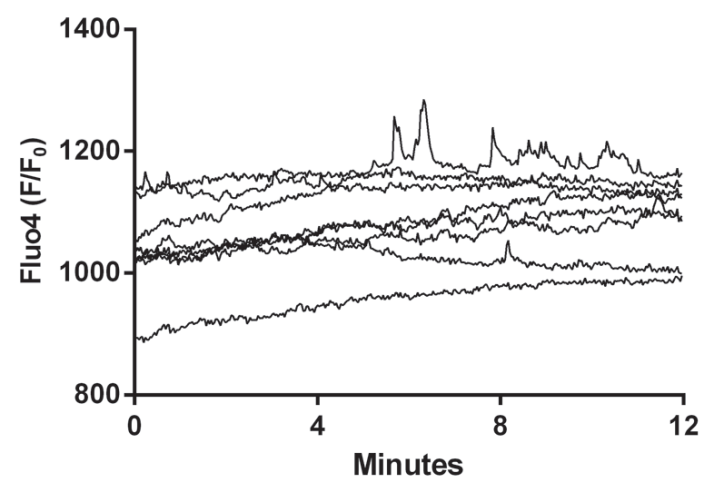

BxPC3-SMAD4+ hsa-miR-1260a

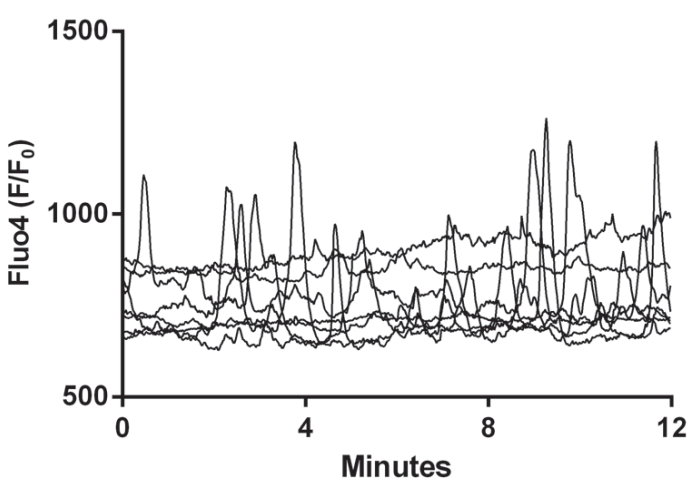

Figure 6: hsa-miR-494-3p and miR-1260a transfection alters intracellular calcium fluxes $\left(\left[\mathrm{Ca}^{2+}\right]_{\mathrm{i}}\right)$ of PBMCs. The variations in $\left[\mathrm{Ca}^{2+}\right]_{i}$ of PBMCs after incubation for 72 hours in complete not transfected or hsa-miR-494-3p and hsa-miR-1260a transfected $\mathrm{BxPC} 3$ and $\mathrm{BxPC} 3-S M A D 4+$ media are shown as Fluo4 F/F $\mathrm{F}_{0}$ ratio. Each graph represents one experiment and each line $\left[\mathrm{Ca}^{2+}\right]_{i}$ of one cell. 
glycolytic enzymes were overexpressed in BxPC3 than in BxPC3-SMAD4+ Exo, and glycolysis was one of the core biological processes significantly altered in an SMAD4 associated manner and this allows us to add SMAD4 to the repertoire of cancer-associated genetic alterations, which include KRAS activating mutations, TP53 loss of function and $M Y C$ overexpression, which regulate the metabolic reprogramming of cancer cells, also known as the Warburg effect [47]. The SMAD4 related enrichment of glycolytic enzymes in cancer derived Exo might underlie the reverse Warburg effect, the metabolic reprogramming involving stromal cells, such as cancer associated fibroblasts, cancer stem cells, and immune cells. We demonstrated that PDAC derived Exo transfer to myeloid cells the glycolytic enzyme activity of LDH, this finding being correlated with a direct and SMAD4-associated impact of Exo on myeloid cell glycolysis, since BxPC3 derived Exo caused a greater glucose consumption and lactate production than BxPC3-SMAD4+ Exo. However Exo might impact on cellular glucose metabolism not only through the transfer of glycolytic enzymes, but also because they might interfere with gene transcription and translation. miRNAs are candidate molecules in this context, and based on this we verified whether one of the most highly expressed miRNA in BxPC3-SMAD4+ derived Exo, the hsa-miR-1260a, could be implicated in the regulation of glycolysis by transfection/inhibition experiments. The forced expression of this miRNA caused a reduced glucose consumption and lactate production in SMAD4-expressing cells suggesting that hsa-miR-1260a
Tumor cell CM

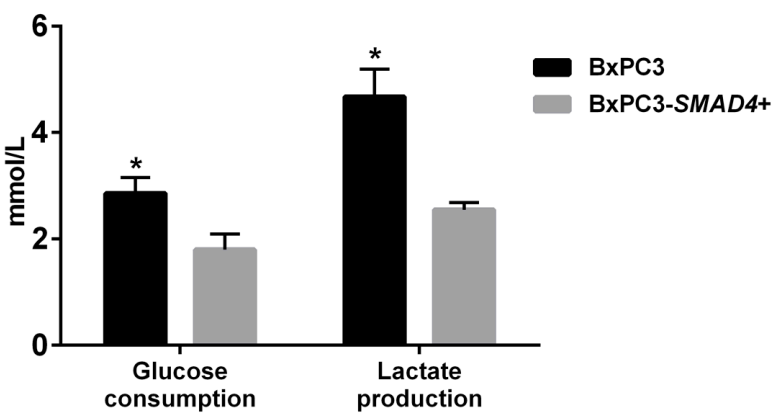

PBMCs cell number

in Exo-enriched media

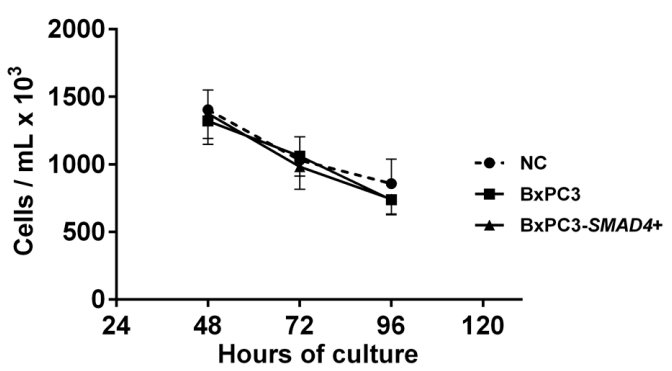

PBMCs Glucose in Exo-enriched media

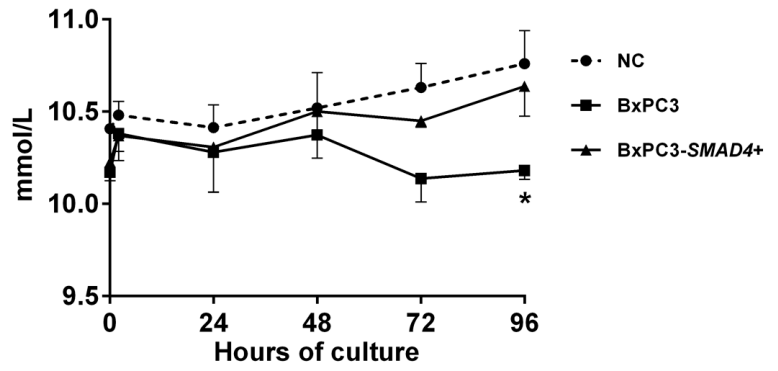

PBMCs Lactate in Exo-enriched media

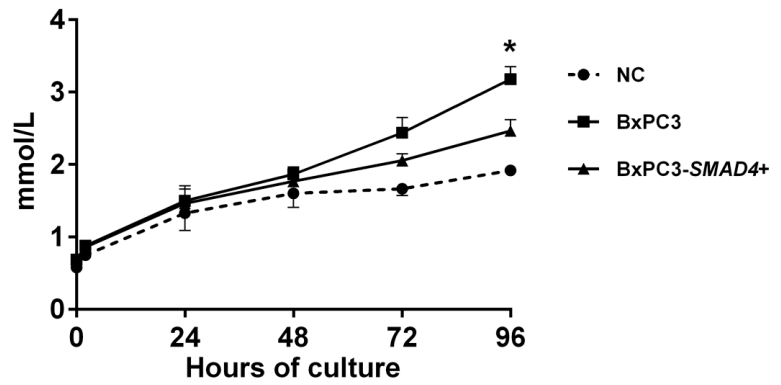

Figure 7: PDAC-derived Exo induce aerobic glycolysis in PBMCs. Upper left panel: Glucose consumption and lactate production of BxPC3 and BxPC3-SMAD4+ cells (mean with standard deviation). The cells were cultured for 4 days in complete media $1 \%$ FCS to obtain conditioned media (CM). Glucose and lactate were measured in non conditioned and in CM from three separate experiments. For any experiment glucose consumption was calculated as the difference between glucose measured in non conditioned $(11.5 \mathrm{mmol} / \mathrm{L}$, mean of three replicates) and in CM. In non conditioned media lactate levels were always below the detection limit $(<0.03 \mathrm{mmol} / \mathrm{L})$, this supporting lactate levels measured in CM as lactate production. *Student's $t$ test for paired data: $t=12.95, p<0.01$ for glucose consumption; $t=9.54$, $p=0.01$ for lactate production. Lower left panel: number of PBMCs cultured in Exo-enriched non conditioned (NC) medium and in Exoenriched BxPC3 and BxPC3-SMAD4+ CM obtained as described in the upper left panel. Mean values (points) with standard deviation (bars) from three independent experiments, each in duplicate, are shown. Two-way Repeated measures analysis of variance: $\mathrm{F}=14.16, p$ $=0.0012$ for time effect; $\mathrm{F}=0.72, \mathrm{p}=0.5101$ for treatment effect; $\mathrm{F}=0.2287, p=0.9190$ for time-treatment interaction. Upper and lower right panels: glucose and lactate measured in the supernatants of PBMCs cultured for 2, 24, 48, 72 and 96 hours in Exo-enriched NC and in Exo-enriched BxPC3 and BxPC3-SMAD4+ CM obtained as described in the upper left panel. Mean values (points) with standard deviation (bars) from three independent experiments, each in duplicate, are shown. Two-way Repeated measures analysis of variance: Time effect: $\mathrm{F}$ $=0.9175, p=0.5077$ for glucose and $\mathrm{F}=49.68, p<0.0001$ for lactate; Treatment effect: $\mathrm{F}=9.943, p=0.0280$ for glucose and $\mathrm{F}=10.11, p$ $=0.0273$ for lactate; Time-treatment interaction: $\mathrm{F}=2.420, p=0.0444$ for glucose and $\mathrm{F}=8.997, p<0.0001$ for lactate. *Tukey's multiple comparison test: $p<0.05$ with respect to NC PBMCs. 
is an antagonist of the Warburg effect. The present study therefore demonstrates that metabolic reprogramming with increased glycolysis and conversion of glucose into lactate is SMAD4 and hsa-miR-1260a dependent and that tumor cells can transfer the propensity to elevated glycolysis to stromal cells via Exo. This finding opens new ways for understanding the relationship between cancer metabolism and immune suppression recently reported to be dependent on the metabolic competition between tumor and immune cells [48].

In conclusion, SMAD4 deletion might underlie a more aggressive PDAC phenotype through Exo transfer to immune cells of proteins and miRNAs that, by altering intracellular calcium and glycolysis, may cause the expansion of immunosuppressive myeloid cells.

\section{MATERIALS AND METHODS}

\section{Cell lines}

The pancreatic cancer cell lines $\mathrm{BxPC} 3$, known to carry a homozygous deletion of the SMAD4/DPC4 gene, and BxPC3-SMAD4+, obtained from the BxPC3 cells stably transfected with the $\mathrm{pBK}$-cytomegalovirus (CMV)-SMAD4/DPC4 expression vector, were used.
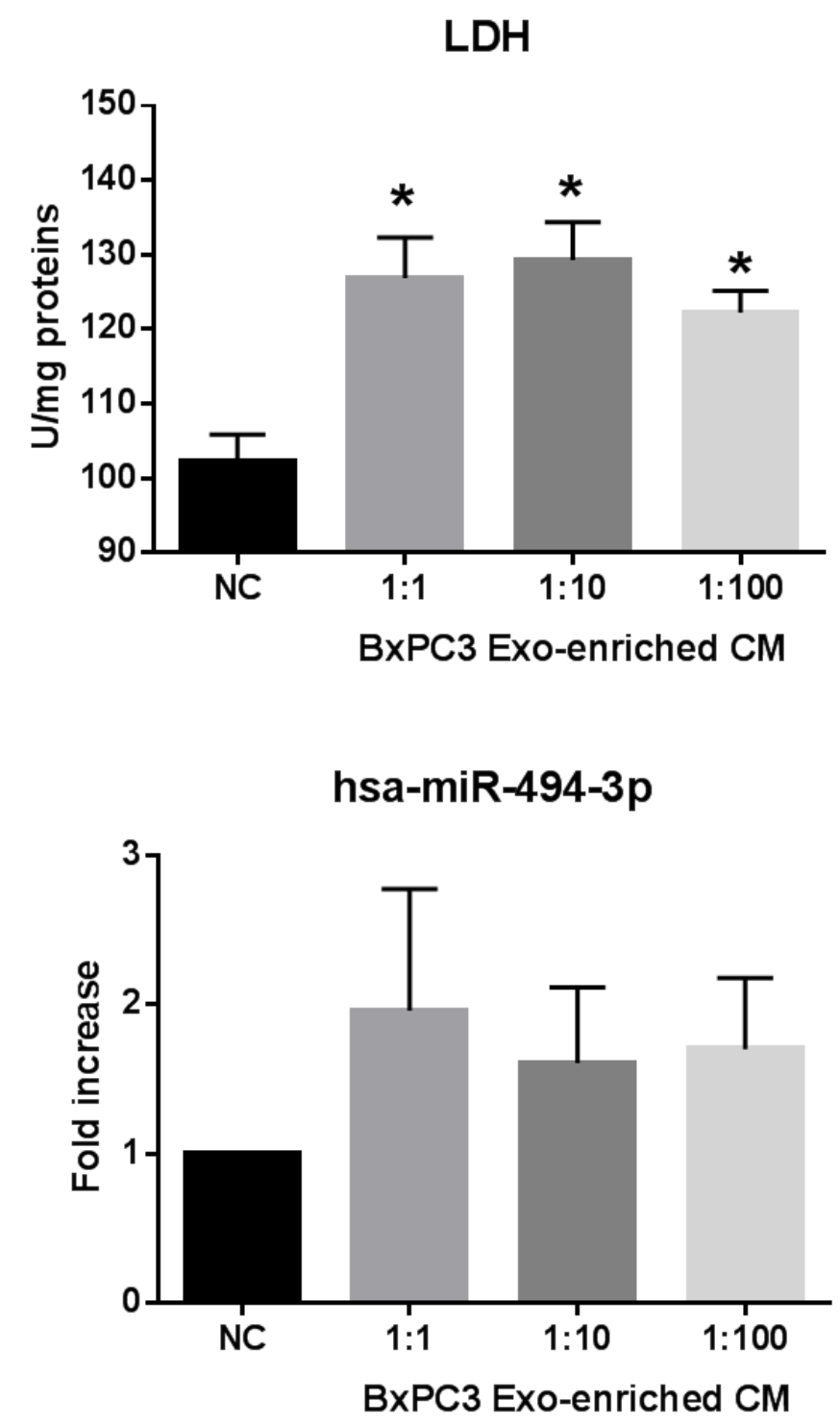

Figure 8: PDAC-derived Exo transfer LDH enzyme activity and hsa-miR-494-3p into PBMCs. Upper panel: LDH activity in PBMCs after they have been cultured in the absence (NC) or in the presence of serially diluted BxPC3 derived Exo for 24 hours. Mean values (columns) with standard deviation (bars) from four independent experiments are shown. *Bonferroni's test for pairwise comparison: $p<0.05$ with respect to NC. Lower panel: hsa-miR-494-3p relative expression in PBMCs after they have been cultured in the absence (NC) or in the presence of serially diluted BxPC3 derived Exo for 24 hours. Mean values (columns) with standard deviation (bars) from four independent experiments are shown. 
The characterization of the cellular model including the validation of the transfection efficacy has been described by us elsewhere [49]. Culture details are reported in Supplementary Methods.

\section{Exo enrichment for cellular experiments}

Non conditioned media, BxPC3 and BxPC3SMAD4+ conditioned media (CM), all containing $1 \%$ FCS, were enriched in Exo following the differential ultracentrifugation procedure detailed in Supplementary Methods.

\section{Isolation of human peripheral blood mononuclear cells (PBMCs)}

Human PBMCs were isolated from blood donors' buffy coats by differential density gradient centrifugation (Histopaque $^{\circledR}$-1077, Sigma-Aldrich, Milano, Italy, F/H). After being washed twice with saline solution to remove contaminating platelets and centrifuged at 1,200 rpm for 10 minutes, PBMCs were treated with a hemolysis solution $\left(\mathrm{NH}_{4} \mathrm{Cl}, \mathrm{KHCO}_{3}\right.$, EDTA $\left.\mathrm{Na}_{4}\right)$ for 10 minutes, centrifuged at 1, $200 \mathrm{rpm}$ for 10 minutes and finally used for the experiments.

\section{Experimental design}

PBMCs were cultured in complete, Exo- free and Exo-enriched CM and non conditioned media. After 4 culture days, PBMCs were analyzed by flow cytometry and cytokines were measured in the supernatants. Intracellular calcium fluxes were analyzed in the same experimental conditions after 3 culture days by epifluorescence (Fluo4).

\section{Flow cytometry analysis}

Human PBMCs from 8 blood donor's buffy coats were seeded in a six well culture plate $\left(6 \times 10^{6}\right.$ in each well) and kept in culture for 96 hours with $3 \mathrm{~mL}$ of complete, Exo-free and Exo-enriched non conditioned, BXPC3 CM and $\mathrm{BxPC} 3-S M A D 4+\mathrm{CM}$ reconstituted with $10 \% \mathrm{FCS}$. After 96 hours, PBMCs were collected by scraping, and analyzed by flow cytometry as detailed in Supplementary Methods.

\section{Cell sorting}

$20 \times 10^{6}$ PBMCs were cultured for $48 \mathrm{~h}$ in $100 \mathrm{~mm}$ culture dishes in $10 \mathrm{ml}$ of BxPC3-SMAD4+ CM. At least 20 culture dishes were prepared. After collection by scraping, $200 \times 10^{6} \mathrm{PBMCs}$ were incubated in the dark for 30 minutes with the following monoclonal antibodies
(Beckman Coulter, Miami, FL, USA): $110 \mu \mathrm{L}$ HLADR-PC5, $80 \mu \mathrm{L}$ CD14-PC7, $80 \mu \mathrm{L}$ CD45-ECD and 80 $\mu \mathrm{L}$ CD11b PE. Afterwards, PBMCs were washed with PBS containing 2\% FCS, centrifuged at $1200 \mathrm{rpm}$ for 10 minutes and re-suspended with PBS containing 2\% FCS to obtain $15 \times 10^{6} \mathrm{PBMCs}$ per $\mathrm{mL}$. The above-described four mononuclear cell subsets were FACS-sorted (BD FACSAria III, BD Biosciences, San Jose, CA, USA). Sorted cells were seeded on coverslips that had been inserted within each well of six well culture plates and cultured for 48 hours in $2 \mathrm{ml}$ of complete control medium before $\left[\mathrm{Ca}^{2+}\right]_{\mathrm{i}}$ fluxes study. After $\left[\mathrm{Ca}^{2+}\right]_{\mathrm{i}}$ fluxes study, each coverslip was also stained in May-Grünwald-Giemsa. This experiment was repeated three times with buffy coats from three blood donors.

\section{Intracellular calcium fluxes analysis}

$2 \times 10^{6}$ PBMC were seeded on coverslips that had been inserted in each well of six well culture plates and cultured for 72 hours in $2 \mathrm{ml}$ of complete or Exo-enriched control, BxPC3 CM, BxPC3-SMAD4+ CM reconstituted at $10 \%$ FCS. Coverslips were then processed for the $\left[\mathrm{Ca}^{2+}\right]_{\mathrm{i}}$ fluxes study as previously described [49], using the intracellular calcium tracer Fluo-4AM (Invitrogen S.R.L.) at $5 \mu \mathrm{M}$. Three independent experiments, each made in triplicate, were performed.

\section{Cytokines assay}

After centrifugation at $1,200 \mathrm{rpm}$ for 10 minutes of PBMCs supernatants after 96 hours culture in the abovedescribed conditions IL-1 $\beta$, IL-4, IL-6, IL-10, TGF- $\beta 1$ and TNF were analyzed by chemiluminescent immunometric assays (Immulite, Siemens Healthcare Diagnostic, UK) according to the manufacturer's specifications. For all the experimental conditions, at least three independent sets of experiments were performed.

\section{Glucose, lactate and lactate dehydrogenase (LDH) assays}

Glucose and lactate in culture supernatants were measured on the automated ARCHITECT System following the manufacturer's instructions (Abbott Laboratories, Abbott Park, IL, USA). LDH enzymatic activity was determined in PBMCs lysates by using the automated COBAS System according to the manufacturer's instructions (Roche Molecular Diagnostics, Pleasanton, CA, USA). 


\section{miRNAs microarray analysis}

The miRNAs expression profiling of $\mathrm{BxPC} 3$ and BxPC3-SMAD4+ CM Exo was performed in duplicate samples using the Agilent SurePrintG3 Human miRNA (8x60K) microarrays (custom design by Comprehensive Biomarker Center, $\mathrm{CBC}$, recently re-named to Hummingbird Diagnostics GmbH, Heidelberg, Germany) as detailed in Supplementary Methods.

\section{miRNA transfection and inhibition experiments}

Human hsa-miR-494-3p and hsa-miR-1260a were transfected (miRIDIAN mimic) and silenced (miRIDIAN Hairpin inhibitor)(Dharmacon, GE Healthcare, UK) in $\mathrm{BxPC} 3$ and $\mathrm{BxPC} 3-S M A D 4+$ cells following the manufacturer's instruction.

\section{SILAC experiment}

BxPC3 and BxPC3-SMAD4+ cell lines were cultured in RPMI 1640 MEDIA FOR SILAC with $10 \%$ dialyzed fetal bovine serum (FBS), with the addition of either with the non-labelled aminoacids Lysin and Arginine (light medium) or with the labelled ${ }^{13} \mathrm{C}_{6}$ Lysine and ${ }^{13} \mathrm{C}_{6}{ }^{15} \mathrm{~N}_{4}$-arginine (heavy medium) (Chemical Research 2000 srl, Rome, Italy). In a second experiment, the same cell lines were cultured by swapping media, $\mathrm{BxPC} 3$ being maintained in heavy medium and $\mathrm{BxPC} 3-$ $S M A D 4+$ maintained in light medium, thus creating two biological replicates of the same experiment. After eight days, cell media were changed with fresh media prepared as specified above but without the serum addition, in order to reduce any contaminant in the proteomic analyses, cells being cultured in this condition for 16 hours before media collection and exosomes enrichment made by ultracentrifugation (Beckman Coulter L-80XP Ultracentrifuge, Type $70 \mathrm{Ti}$ rotor) as detailed in supplementary methods. The ratios for light/ heavy and heavy/light were calculated for each identified protein of the two experiments. Proteins were considered significantly altered if the average value, calculated for the two ratios, was above 1.5 or below 0.667

\section{Statistical analysis}

The statistical analysis of data was made by Repeated measures ANOVA, Tukey's multiple comparisons test, Student's t test for paired data and the chi square test using the GraphPad prism software (ver 6.04).

\section{Abbreviations}

$\mathrm{CM}$, conditioned media; DCs, dendritic cells; Exo, exosomes; FACS, Fluorescence-activated cell sorting; GM-CSF, granulocyte-macrophage colony-stimulating factor; IL, interleukin; LDH, lactate dehydrogenase; MDSCs, myeloid derived suppressor cells; PanINs, pancreatic intraepithelial neoplasms; PBMCs, peripheral blood mononuclear cells; PDAC, Pancreatic ductal adenocarcinoma; TAM, tumor associated macrophages; TGF, transforming growth factor; TNF, tumor necrosis factor; VDAC, voltage dependent anion selective channel protein.

\section{Author contributions}

D.Ba. conceived and designed the study. E.G., P.F., S.F., A.A., D.Bo., C.-F.Z., C.F., S.M. and F.N. performed the experiments. A.P., G.A. and C.F. performed mass spectrometry analysis. A.A., T.B. and T.L. provided valuable reagents and performed microRNA analysis. D.Ba. and E.G. wrote the paper. S.P., G.B. and M.P. revised the work. All authors read and approved the final manuscript.

\section{ACKNOWLEDGMENTS}

The authors wish to thank the Cassa di Risparmio di Padova e Rovigo (Cariparo) Holding for funding the acquisition of the LTQ-Orbitrap XL mass spectrometer. The authors also thank Sara Jane Pearcey for her valuable help with the English.

\section{GRANT SUPPORT} Onlus".

Contract grant sponsor: "AssociazioneWirsung-

\section{CONFLICTS OF INTEREST}

All authors declare that they have no conflicts of interest to disclose.

\section{Editorial note}

This paper has been accepted based in part on peerreview conducted by another journal and the authors' response and revisions as well as expedited peer-review in Oncotarget.

\section{REFERENCES}

1. Siegel RL, Miller KD, Jemal A. Cancer Statistics, 2017. CA Cancer J Clin. 2017; 67:7-30. 
2. Ryan DP, Hong TS, Bardeesy N. Pancreatic adenocarcinoma. N Engl J Med. 2014; 371:1039-1049.

3. Bailey P, Chang DK, Nones K, Johns AL, Patch AM, Gingras MC, Miller DK, Christ AN, Bruxner TJ, Quinn MC, Nourse C, Murtaugh LC, Harliwong I, et al. Genomic analyses identify molecular subtypes of pancreatic cancer. Nature. 2016; 531:47-52.

4. Waddell N, Pajic M, Patch AM, Chang DK, Kassahn KS, Bailey P, Johns AL, Miller D, Nones K, Quek K, Quinn MC, Robertson AJ, Fadlullah MZ, et al. Whole genomes redefine the mutational landscape of pancreatic cancer. Nature. 2015; 518:495-501.

5. Witkiewicz AK, McMillan EA, Balaji U, Baek G, Lin WC, Mansour J, Mollaee M, Wagner KU, Koduru P, Yopp A, Choti MA, Yeo CJ, McCue P, et al. Whole-exome sequencing of pancreatic cancer defines genetic diversity and therapeutic targets. Nat Commun. 2015; 6:6744.

6. Iacobuzio-Donahue $\mathrm{CA}, \mathrm{Fu} \mathrm{B}$, Yachida $\mathrm{S}$, Luo M, Abe H, Henderson CM, Vilardell F, Wang Z, Keller JW, Banerjee P, Herman JM, Cameron JL, Yeo CJ, et al. DPC4 gene status of the primary carcinoma correlates with patterns of failure in patients with pancreatic cancer. J Clin Oncol. 2009; 27:1806-1813.

7. Oshima M, Okano K, Muraki S, Haba R, Maeba T, Suzuki Y, Yachida S. Immunohistochemically detected expression of 3 major genes (CDKN2A/p16, TP53, and SMAD4/ DPC4) strongly predicts survival in patients with resectable pancreatic cancer. Ann Surg. 2013; 258:336-346.

8. Fullerton PT, Creighton CJ, Matzuk MM. Insights Into SMAD4 Loss in Pancreatic Cancer From Inducible Restoration of TGF- $\beta$ Signaling. Mol Endocrinol. 2015; 29:1440-1453.

9. Horbelt D, Denkis A, Knaus P. A portrait of Transforming Growth Factor $\beta$ superfamily signalling: Background matters. Int J Biochem Cell Biol. 2012; 44:469-474.

10. Whittle MC, Izeradjene K, Rani PG, Feng L, Carlson MA, DelGiorno KE, Wood LD, Goggins M, Hruban RH, Chang AE, Calses P, Thorsen SM, Hingorani SR. RUNX3 Controls a Metastatic Switch in Pancreatic Ductal Adenocarcinoma. Cell. 2015; 161:1345-1360.

11. Basso D, Fogar P, Plebani M. The S100A8/A9 complex reduces CTLA4 expression by immature myeloid cells: Implications for pancreatic cancer-driven immunosuppression. Oncoimmunology. 2013; 2:e24441.

12. Hu Y, Lee YT, Kaech SM, Garvy B, Cauley LS. Smad4 Promotes Differentiation of Effector and Circulating Memory CD8 T Cells but Is Dispensable for TissueResident Memory CD8 T Cells. J Immunol. 2015; 194:2407-2414.

13. Shi C, Washington MK, Chaturvedi R, Drosos Y, Revetta FL, Weaver CJ, Buzhardt E, Yull FE, Blackwell TS, SosaPineda B, Whitehead RH, Beauchamp RD, Wilson KT, et al. Fibrogenesis in pancreatic cancer is a dynamic process regulated by macrophage-stellate cell interaction. Lab
Invest. 2014; 94:409-421.

14. Stromnes IM, Greenberg PD, Hingorani SR. Molecular pathways: myeloid complicity in cancer. Clin Cancer Res. 2014; 20:5157-5170.

15. Clark CE, Beatty GL, Vonderheide RH. Immunosurveillance of pancreatic adenocarcinoma: insights from genetically engineered mouse models of cancer. Cancer Lett. 2009; 279:1-7.

16. Basso D, Fogar P, Falconi M, Fadi E, Sperti C, Frasson C, Greco E, Tamburrino D, Teolato S, Moz S, Bozzato D, Pelloso M, Padoan A, et al. Pancreatic tumors and immature immunosuppressive myeloid cells in blood and spleen: role of inhibitory co-stimulatory molecules PDL1 and CTLA4. An in vivo and in vitro study. PLoS One. 2013; 8:e54824.

17. Ene-Obong A, Clear AJ, Watt J, Wang J, Fatah R, Riches JC, Marshall JF, Chin-Aleong J, Chelala C, Gribben JG, Ramsay AG, Kocher HM. Activated pancreatic stellate cells sequester $\mathrm{CD} 8+\mathrm{T}$ cells to reduce their infiltration of the juxtatumoral compartment of pancreatic ductal adenocarcinoma. Gastroenterology. 2013; 145:1121-1132.

18. Ino Y, Yamazaki-Itoh R, Shimada K, Iwasaki M, Kosuge T, Kanai Y, Hiraoka N. Immune cell infiltration as an indicator of the immune microenvironment of pancreatic cancer. $\mathrm{Br} \mathrm{J}$ Cancer. 2013; 108:914-923.

19. Mitchem JB, Brennan DJ, Knolhoff BL, Belt BA, Zhu Y, Sanford DE, Belaygorod L, Carpenter D, Collins L, Piwnica-Worms D, Hewitt S, Udupi GM, Gallagher WM, et al. Targeting tumor-infiltrating macrophages decreases tumor-initiating cells, relieves immunosuppression, and improves chemotherapeutic responses. Cancer Res. 2013; 73:1128-1141.

20. Stromnes IM, Brockenbrough JS, Izeradjene K, Carlson MA, Cuevas C, Simmons RM, Greenberg PD, Hingorani SR. Targeted depletion of an MDSC subset unmasks pancreatic ductal adenocarcinoma to adaptive immunity. Gut. 2014; 63:1769-1781.

21. Tang Y, Xu X, Guo S, Zhang C, Tang Y, Tian Y, Ni B, Lu $\mathrm{B}$, Wang $\mathrm{H}$. An increased abundance of tumor-infiltrating regulatory $\mathrm{T}$ cells is correlated with the progression and prognosis of pancreatic ductal adenocarcinoma. PLoS One. 2014; 9:e91551.

22. Liou GY, Storz P. Inflammatory macrophages in pancreatic acinar cell metaplasia and initiation of pancreatic cancer. Oncoscience. 2015; 2:247-251.

23. Karakhanova S, Link J, Heinrich M, Shevchenko I, Yang Y, Hassenpflug M, Bunge H, von Ahn K, Brecht R, Mathes A, Maier C, Umansky V, Werner J, et al. Characterization of myeloid leukocytes and soluble mediators in pancreatic cancer: importance of myeloid-derived suppressor cells. Oncoimmunology. 2015; 4:e998519.

24. Clark CE, Hingorani SR, Mick R, Combs C, Tuveson DA, Vonderheide RH. Dynamics of the immune reaction to pancreatic cancer from inception to invasion. Cancer Res. 2007; 67:9518-9527. 
25. Trikha P, Carson WE III. Signaling pathways involved in MDSC regulation. BBA - Rev Cancer. 2014; 1846:55-65.

26. Zhang L, Wrana JL. The emerging role of exosomes in Wnt secretion and transport. Curr Opin Genet Dev. 2014; 27C:14-19.

27. Gajos-Michniewicz A, Duechler M, Czyz M. MiRNA in melanoma-derived exosomes. Cancer Lett. 2014; 347:2937.

28. Melo SA, Sugimoto H, O'Connell JT, Kato N, Villanueva A, Vidal A, Qiu L, Vitkin E, Perelman LT, Melo CA, Lucci A, Ivan C, Calin GA, et al. Cancer exosomes perform cell-independent microRNA biogenesis and promote tumorigenesis. Cancer Cell. 2014; 26:707-721.

29. Costa-Silva B, Aiello NM, Ocean AJ, Singh S, Zhang H, Thakur BK, Becker A, Hoshino A, Mark MT, Molina H, Xiang J, Zhang T, Theilen TM, et al. Pancreatic cancer exosomes initiate pre-metastatic niche formation in the liver. Nat Cell Biol. 2015; 17:816-826.

30. Wei Y, Lai X, Yu S, Chen S, Ma Y, Zhang Y, Li H, Zhu X, Yao L, Zhang J. Exosomal miR-221/222 enhances tamoxifen resistance in recipient ER-positive breast cancer cells. Breast Cancer Res Treat. 2014; 147:423-431.

31. Filipazzi P, Bürdek M, Villa A, Rivoltini L, Huber $\mathrm{V}$. Recent advances on the role of tumor exosomes in immunosuppression and disease progression. Semin Cancer Biol. 2012; 22:342-349.

32. Bretz NP, Ridinger J, Rupp AK, Rimbach K, Keller S, Rupp C, Marmé F, Umansky L, Umansky V, Eigenbrod T, Sammar M, Altevogt P. Body fluid exosomes promote secretion of inflammatory cytokines in monocytic cells via Toll-like receptor signaling. J Biol Chem. 2013; 288:36691-36702.

33. Zhou M, Chen J, Zhou L, Chen W, Ding G, Cao L. Pancreatic cancer derived exosomes regulate the expression of TLR4 in dendritic cells via miR-203. Cell Immunol. 2014; 292:65-69.

34. Liu W, Matsumori A. Calcium channel blockers and modulation of innate immunity. Curr Opin Infect Dis. 2011; 24:254-258.

35. Rooke R. Can calcium signaling be harnessed for cancer immunotherapy? BBA - Mol Cell Res. 2014; 1843:23342340.

36. Ying H, Dey P, Yao W, Kimmelman AC, Draetta GF, Maitra A, DePinho RA. Genetics and biology of pancreatic ductal adenocarcinoma. Genes Dev. 2016; 30:355-385.

37. Helm O, Mennrich R, Petrick D, Goebel L, Freitag-Wolf S, Röder C, Kalthoff H, Röcken C, Sipos B, Kabelitz D, Schäfer H, Oberg HH, Wesch D, et al. Comparative characterization of stroma cells and ductal epithelium in chronic pancreatitis and pancreatic ductal adenocarcinoma. PLoS One. 2014; 9:e94357.
38. Burke M, Choksawangkarn W, Edwards N, OstrandRosenberg S, Fenselau C. Exosomes from myeloid-derived suppressor cells carry biologically active proteins. J Proteome Res. 2014; 13:836-843.

39. Ono M, Kosaka N, Tominaga N, Yoshioka Y, Takeshita F, Takahashi RU, Yoshida M, Tsuda H, Tamura K, Ochiya $\mathrm{T}$. Exosomes from bone marrow mesenchymal stem cells contain a microRNA that promotes dormancy in metastatic breast cancer cells. Sci Signal. 2014; 7:ra63.

40. Song X, Ding Y, Liu G, Yang X, Zhao R, Zhang Y, Zhao X, Anderson GJ, Nie G. Cancer cell-derived exosomes induce mitogen-activated protein kinase-dependent monocyte survival by transport of functional receptor tyrosine kinases. J Biol Chem. 2016; 291:8453-8464.

41. Mao Y, Poschke I, Kiessling R. Tumour-induced immune suppression: role of inflammatory mediators released by myelomonocytic cells. J Intern Med. 2014; 276:154-170.

42. Feske S, Wulff H, Skolnik EY. Ion channels in innate and adaptive immunity. Annu Rev Immunol. 2015; 33:291-353.

43. Vaeth M, Zee I, Concepcion AR, Maus M, Shaw P, PortalCelhay C, Zahra A, Kozhaya L, Weidinger C, Philips J, Unutmaz D, Feske S. Ca2+ signaling but not store-operated $\mathrm{Ca} 2+$ entry is required for the function of macrophages and dendritic cells. J Immunol. 2015; 195:1202-1217.

44. Li L, Li Z, Kong X, Xie D, Jia Z, Jiang W, Cui J, Du Y, Wei D, Huang S, Xie K. Down-regulation of microRNA-494 via loss of SMAD4 increases FOXM1 and $\beta$-catenin signaling in pancreatic ductal adenocarcinoma cells. Gastroenterology. 2014; 147:485-497.

45. Huang $\mathrm{H}, \mathrm{Hu} \mathrm{X}$, Eno CO, Zhao G, Li C, White C. An interaction between $\mathrm{Bcl}-\mathrm{xL}$ and the voltage-dependent anion channel (VDAC) promotes mitochondrial $\mathrm{Ca} 2+$ uptake. J Biol Chem. 2013; 288:19870-19881.

46. Wang Z, Li Z, Wang Y, Cao D, Wang X, Jiang M, Li M, Yan X, Li Y, Liu Y, Luo F. Versican silencing improves the antitumor efficacy of endostatin by alleviating its induced inflammatory and immunosuppressive changes in the tumor microenvironment. Oncol Rep. 2015; 33:2981-2991.

47. Bhattacharya B, Mohd Omar MF, Soong R. The Warburg effect and drug resistance. Br J Pharmacol. 2016; 173:970979.

48. Sukumar M, Roychoudhuri R, Restifo NP. Nutrient competition: a new axis of tumor immunosuppression. Cell 2015; 162:1206-1208.

49. Moz S, Basso D, Bozzato D, Galozzi P, Navaglia F, Negm $\mathrm{OH}$, Arrigoni G, Zambon CF, Padoan A, Tighe P, Todd I, Franchin C, Pedrazzoli S, et al. SMAD4 loss enables EGF, TGF $\beta 1$ and S100A8/A9 induced activation of critical pathways to invasion in human pancreatic adenocarcinoma cells. Oncotarget. 2016;7:69927-69944. doi: 10.18632/ oncotarget. 12068 . 